\title{
A nested-grid Boussinesq-type approach to modelling dispersive propagation and runup of landslide-generated tsunamis
}

\author{
H. Zhou ${ }^{1,2}$, C. W. Moore ${ }^{1,2}$, Y. Wei ${ }^{1,2}$, and V. V. Titov ${ }^{1}$ \\ ${ }^{1}$ Pacific Marine Environmental Laboratory, NOAA, Seattle, WA 98115, USA \\ ${ }^{2}$ Joint Institute for the Study of the Atmosphere and Ocean, University of Washington, Seattle, WA 98105, USA
}

Received: 2 December 2010 - Revised: 25 August 2011 - Accepted: 5 September 2011 - Published: 10 October 2011

\begin{abstract}
A tsunami generated by large-volume landslide can propagate across the ocean and flood communities around the basin. The evolution of landslide-generated tsunamis is affected by the effects of frequency dispersion and involves processes of different temporal and spacial scales. In this paper, we develop a numerical approach employing the weakly nonlinear and fully nonlinear Boussinesq-type theories and nested computational grids. The propagation in a large domain is simulated with the weakly nonlinear model in a geographical reference frame. The nearshore wave evolution and runup are computed with the fully nonlinear model. Nested grids are employed to zoom simulations from larger to smaller domains at successively increasing resolutions. The models and the nesting scheme are validated for theoretical analysis, laboratory experiments and a historical tsunami event. By applying this approach, we also investigate the potential tsunami impact on the US east coast due to the possible landslide on La Palma Island. The scenario employed in this study represents an event of extremely low probability.
\end{abstract}

\section{Introduction}

Besides earthquakes, submarine and subaerial landslides are probably the second most common cause of tsunamis (Synolakis and Bernard, 2006). Most landslide-generated tsunamis are localized events that cause severe damage to limited areas (e.g. Synolakis et al., 2002). Investigations of historical

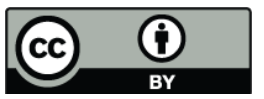

Correspondence to: $\mathrm{H}$. Zhou (hongqiang.zhou@noaa.gov) traces also indicate that very large landslides have happened underwater and generated mega tsunamis causing devastations in large areas (Ward, 2001). Although a scenario of very low probability, the potential impact of such events needs to be assessed in some circumstances, such as the planning of nuclear facilities.

Under specific assumptions, the spreading landslide can be treated as a long wave described in the depth-integrated theories (e.g. Savage and Hutter, 1989; Jiang and LeBlond, 1992, 1993; Rabinovich et al., 1999; Imran et al., 2001; Skvortsov and Bornhold, 2007), or a flow with strong turbulence and vorticity which can be predicted through the Navier-Stokes theory (e.g. Gisler et al., 2006; Wünnemann et al., 2006; Abadie et al., 2010). In an alternative approach developed by Ward and Day (2006), the landslide debris is treated as a granular mass, and the motion of each particle is computed under the gravitational and centripetal accelerations. The dynamic process of tsunami generation due to seabed disturbance can be approximated by the shallow water equations (e.g. Jiang and LeBlond, 1992, 1993; Rabinovich et al., 1999), the Boussinesq-type theories (e.g. Lynett and Liu, 2002; Fuhrman and Madsen, 2009; Zhou and Teng, 2010), the nonlinear potential flow theory (e.g. Grilli et al., 2002; Grilli and Watts, 2005), or the Navier-Stokes theory (e.g. Mader, 1984; Liu et al., 2005; Yuk et al., 2006). For landslide-generated tsunamis, frequency dispersion is an important factor governing the wave evolution (Mader, 2001; Watts et al., 2003; Løvholt et al., 2008), which may be modelled through the Boussinesq-type theories.

Most of the existing Boussinesq-type numerical codes, such as FUNWAVE ("Fully Nonlinear Boussinesq Wave Model") (Wei et al., 1995; Wei and Kirby, 1995; Kennedy et al., 2000; Chen et al., 2000) and COULWAVE ("Cornell

Published by Copernicus Publications on behalf of the European Geosciences Union. 


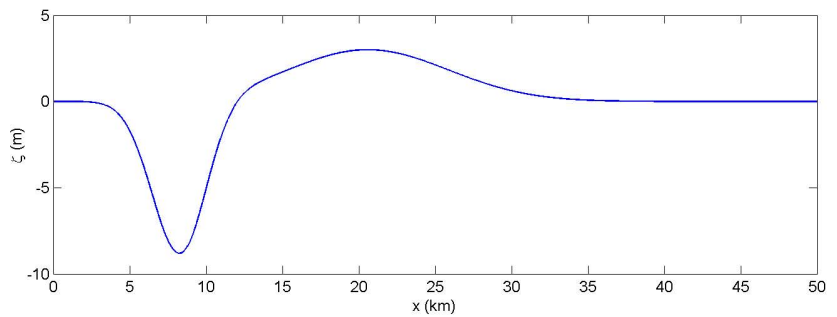

Fig. 1. The leading depression $\mathrm{N}$-wave shape.

University Long and Intermediate Wave Modelling Package") (Lynett et al., 2002), are originally developed for smallscale nearshore wave transformation and runup. For largescale simulations of tsunamis, these codes have also been applied at low resolutions (Watts et al., 2003; Dalrymple et al., 2006; Grilli et al., 2007; Ioualalen et al., 2007; Geist et al., 2009). We note the propagation and runup of tsunamis involve processes of very different scales: from thousands of kilometres in a basin to hundreds of metres in a bay. Different physical features are also present in different stages and require specific considerations. Applying numerical models in a single computational domain at a constant grid spacing may either limit the application of high resolution, or unnecessarily consume large amount of computer resources.

A common approach to multi-stage tsunami simulations is to employ nested grids: the areas of interest are covered by high-resolution grids nested to low-resolution ones over larger domains. Most existing nested-grid tsunami simulating packages, such as MOST ("Method of Splitting Tsunami”) (Titov and González, 1997), TUNAMI-N2 (Imamura, 1996), COMCOT ("Cornell Multi-grid Coupled Tsunami Model") (Liu et al., 1998), and MIKE 21 (Gayer et al., 2010), are based on the shallow water equations which have good applications to seismically generated long waves. In the study by Grilli et al. (2010), tsunami propagation and runup are split into two stages, both modelled with FUNWAVE. At first, the large-scale propagation is simulated at a resolution of $2^{\prime}$. Computational results in this stage are interpolated and input into higher-resolution coastal grids as initial conditions. Løvholt et al. (2010) coupled a global Boussinesq solver, GloBouss, with MOST through the ComMIT ("Community Modelling Interface for Tsunamis") interface (Titov et al., 2011). In their study, the oceanic propagation of dispersive tsunamis is simulated with GloBouss; results from GloBouss are input along the outermost grid boundaries in MOST, which simulates the nearshore propagation and runup in three levels of nested grids.

In this paper, we develop a numerical approach employing the Boussinesq-type theories and nested grids, which may be applied for the dispersive propagation and runup of tsunamis generated by the submarine and subaerial landslides. In a large domain, the weakly nonlinear model is applied to the oceanic propagation of tsunamis; the nearshore propagation
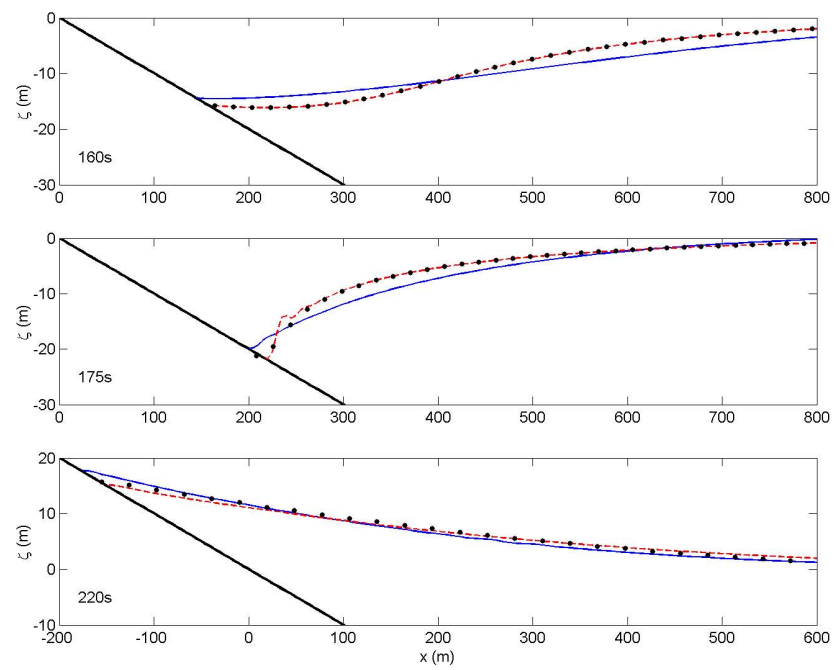

Fig. 2. Water surface profiles given by the analytical solution (.), simulated with the FB model (-) and non-dispersive model (- -).

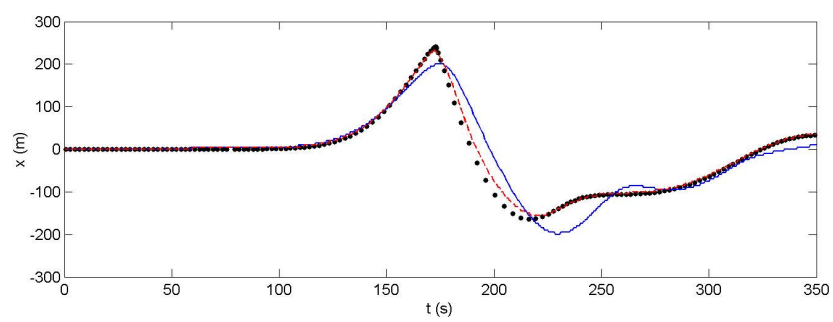

Fig. 3. Time series of shoreline positions given by the analytical solution (.), simulated with the FB model (-) and non-dispersive model (- -).

and runup are simulated with the fully nonlinear model at higher resolutions. A one-way nesting scheme is employed to transfer data from an outer grid to a nested one in forms of precomputed input boundary conditions. This approach is then applied to simulate the propagation of a hypothetical tsunami due to the potential landslide on La Palma Island, and its runup on the US east coast. The initial wave profile in the hypothetical tsunami is configured based on a numerical scenario of Gisler et al. (2006).

\section{Numerical approach}

Tsunami propagation in deep ocean and offshore intermediate water can be described with the Boussinesq theory of Nwogu (1993), which assumes that $O(\epsilon)=O\left(\mu^{2}\right) \ll O(1)$, where $\epsilon=a_{0} / h_{0}$ and $\mu=h_{0} / l_{0}$ are parameters of nonlinearity and dispersion with $a_{0}, h_{0}$ and $l_{0}$ being the characteristic wave amplitude, water depth and wavelength, respectively. In this theory, only the lowest-order nonlinear and dispersive terms are retained. Analysis shows this theory has good approximation to the linear dispersion relation for 


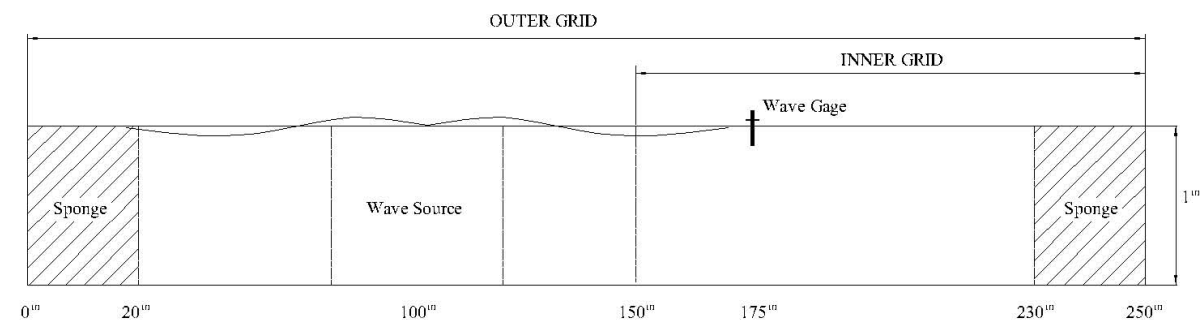

Fig. 4. Sketch of the water flume and computational grids. The plot is not on scale.
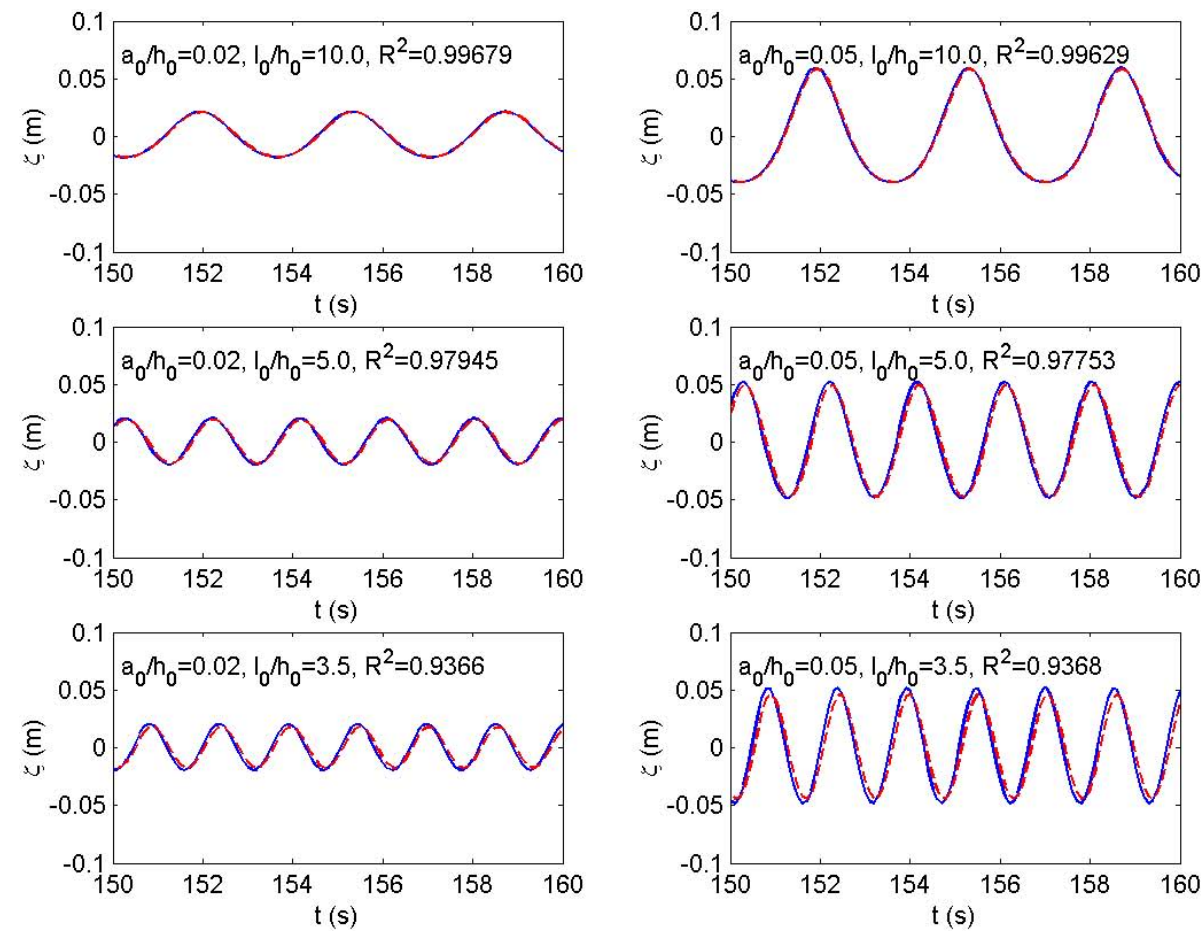

Fig. 5. Time series of water surface elevations in the 1-D tests with periodic waves, computed in outer grid (-) and inner grid (- -).

waves of $h_{0} / l_{0} \leq 1 / 2$. The original equations are described in the Cartesian coordinates. In order to consider the Earth surface curvature in basin-scale simulations, new forms of the Boussinesq theory have also been developed in geographical coordinates, i.e., longitudes $(\phi)$ and latitudes $(\theta)$ (e.g. Pedersen and Løvholt, 2008; Løvholt et al., 2008, 2010; Kirby et al., 2009). In this study, we simply convert the equations of Nwogu (1993) into geographical coordinates. In addition, Coriolis' term is also included. These equations are presented in the Appendix.

As waves approach the shorelines in shallow water, wave heights increase and the nonlinear effects become stronger. This process can be described with the fully nonlinear Boussinesq-type theory derived by Wei et al. (1995), where the assumption of weak nonlinearity is dropped, i.e., $O(\epsilon)=O(1)$. Besides the original form in the Cartesian coordinates, Shi et al. (2002) have also converted these equations into the generalized curvilinear coordinates to improve the model accuracy in areas with irregular shorelines. In the present study, we employ Wei et al.'s (1995) original equations. In order to approximate the energy dissipation due to wave breaking, this model has been improved with the eddy viscosity formulation (Kennedy et al., 2000). In this approach, the intensity of the artificial eddy viscosity term is determined empirically involving four quantities: the thresholds for the breaking event to start $\left(\zeta_{\mathrm{t}}^{\mathrm{I}}\right)$ and to end $\left(\zeta_{\mathrm{t}}^{\mathrm{F}}\right)$, a transition time $\left(T^{*}\right)$ and a mixing length coefficient $\left(\delta_{b}\right)$. These quantities have been calibrated in numerous studies (Kennedy et al., 2000; Lynett, 2002; Roeber et al., 2010). In this study, we employ the ones determined by Lynett (2002) as $\zeta_{\mathrm{t}}^{\mathrm{I}}=0.65 \sqrt{g H}, \zeta_{\mathrm{t}}^{\mathrm{F}}=0.08 \sqrt{g H}, T^{*}=8.0 \sqrt{g H}$ and $\delta_{b}=6.5$, where $g$ is gravitational acceleration and $H$ is the total water depth including water surface elevation and still water depth. We note that although with this improvement, 


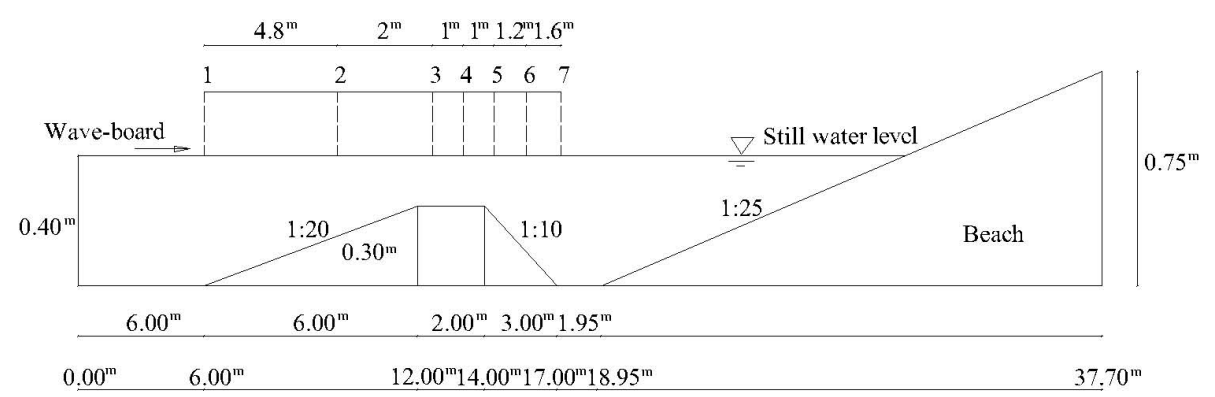

Fig. 6. Schematic diagram of Beji and Battjies' (1994) experimental setup.

application of the Boussinesq-type theories shall still be limited to the processes where the horizontal vorticity is not strong and air-water mixing is not significant. This is posed by the basic assumptions of these theories.

In shallow water, the waves may lose a great amount of energy through frictional dissipation. In both theories, we approximate this effect by using a constant Manning's roughness coefficient. The shear stress along the seabed can be determined as

$\tau=\frac{1}{2} \rho C_{\mathrm{f}}\left|\boldsymbol{u}_{b}\right| \boldsymbol{u}_{b}$,

where $\boldsymbol{u}_{b}$ is the water velocity on the bottom boundary, $\rho$ is density of water, $C_{\mathrm{f}}$ is the friction coefficient which is a function of water depth $H$ and Manning's coefficient $n$, i.e.,

$C_{\mathrm{f}}=\frac{g}{H^{1 / 3}}\left(\frac{n}{k}\right)^{2}$

in which $k=1.0 \mathrm{~m}^{1 / 3} / \mathrm{s}$ is a constant. This formulation is originally designed for steady flows and has also been widely employed in nearshore wave processes (e.g. Liu et al., 1995; Titov and González, 1997).

The equations in both theories are solved numerically through the finite difference algorithm developed by Wei et al. (1995). Thereafter, in this paper, we denote the weakly nonlinear model as GB and the fully nonlinear model as FB. In both models, the slot scheme developed by Kennedy et al. (2000) and Chen et al. (2000) is employed to track the moving shorelines. Shapiro's (1970) nine-point numerical filter is applied in the numerical models over every 5-20 time steps to remove the high-frequency noise due to high-order derivatives in the model equations. In cases with the runup and overtopping of highly nonlinear breaking waves, the fourthorder nine-point Savitzky-Golay filter is employed to replace the Shapiro type.

A simple one-way nesting scheme can be employed to transfer data from an outer computational grid to a nested inner grid. Computed time series of water surface elevations $(\zeta)$ and water velocities $\left(\boldsymbol{u}_{\alpha}\right)$ in the outer grid are first interpolated along the boundaries of the inner grid by using the Lagrangian interpolation method, and then input into the inner grid as precomputed input boundary conditions. We note numerical dispersion is mainly dependent upon the size of grid cells. As a result of different grid spacings, discontinuity of computed water surface profiles may be present across the boundaries of nested grids. To minimize this effect, the ratio of grid spacings is always kept small between inner and outer grids, and the grid boundaries are usually placed in deeper water where wavelengths are relatively longer.

\section{Validations}

\subsection{Tsunami runup onto a plane beach}

In this study, we first validate the slot scheme through a benchmark problem for the long wave runup onto a plane beach (Liu et al., 2008). The problem considers a uniformly sloping incline of $1 / 10$ and an initial leading depression $\mathrm{N}$ wave shown in Fig. 1. The initial water velocities are zero everywhere. An analytical solution to the nonlinear shallow water equations is derived for this problem by Carrier et al. (2003). We simulate this process with the full FB model and a non-dispersive version where all the dispersive terms are turned off. The simulations are conducted in one dimension (1-D) at a spatial resolution of $5.0 \mathrm{~m}$ and constant time step of $0.005 \mathrm{~s}$. Figure 2 compares the water surface profiles between the analytical solution and numerical simulations. As the analytical solution is derived from the shallow water equations, we have a very good agreement between it and the non-dispersive simulation. The same phenomenon is also observed in the time series of shoreline positions in Fig. 3. Besides the accuracy of the slot scheme, this test also suggests frequency dispersion may affect the process of long-wave runup onto a plane beach.

\subsection{Tests on the nesting scheme}

We investigate the accuracy of the nesting scheme in a series of quasi 1-D numerical experiments employing a water flume $250 \mathrm{~m}$ long and $1.0 \mathrm{~m}$ wide with still water depth of $1.0 \mathrm{~m}$. Periodic waves are generated within this flume through the linear source function derived by Wei et al. (1999). Sponge layers are placed in front of both ends of the flume to prevent incoming waves from being reflected back. Figure 4 is 

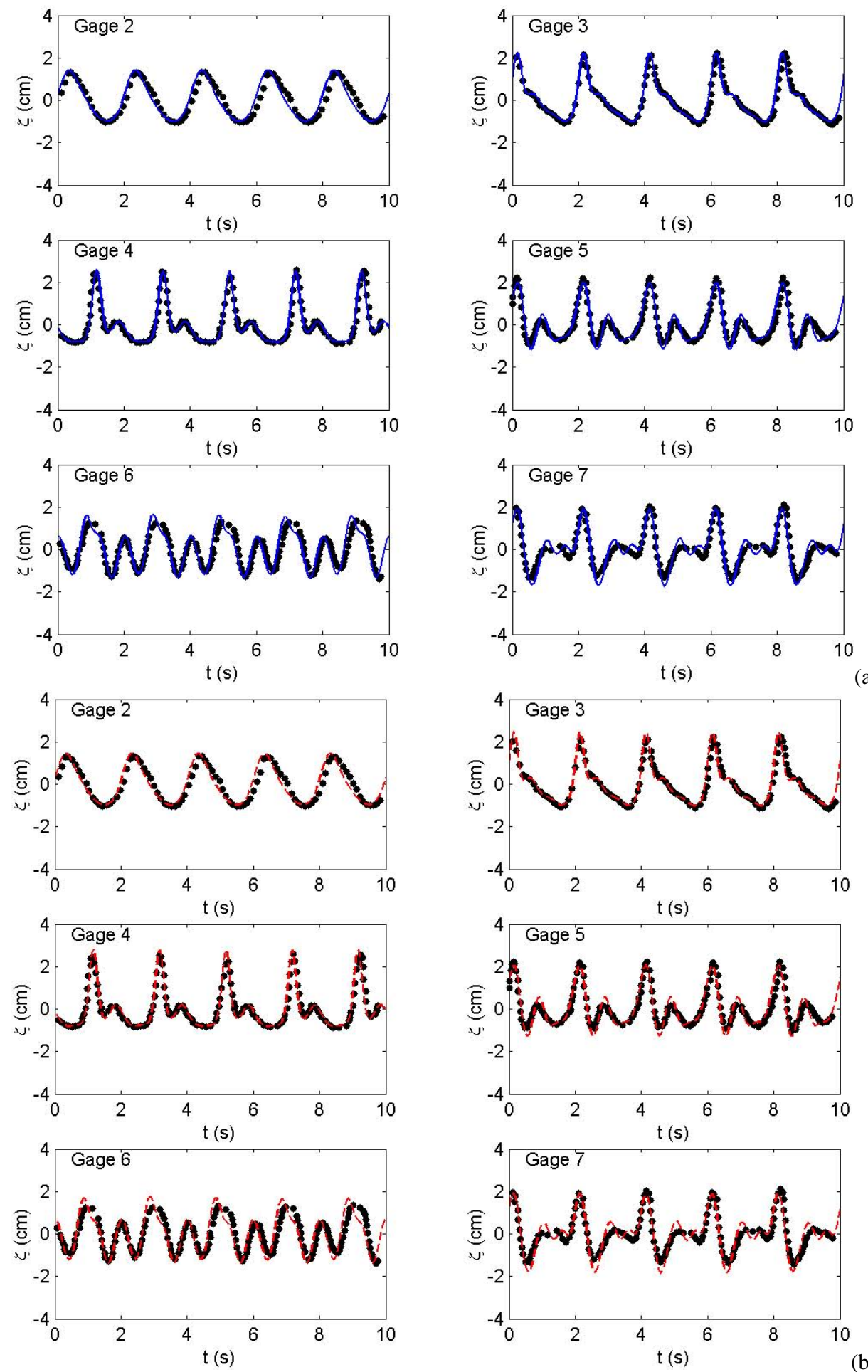

Fig. 7. Time series of water surface elevations in Beji and Battjies' (1994) experiment: FB (-), GB (- -) and measurements (.).

a sketch of the flume and computational grids. Grid spacings of 0.1 and $0.02 \mathrm{~m}$ are applied along the direction of wave propagation in the outer and inner grids, respectively. Along the transverse direction, the length of grid cells is always $0.1 \mathrm{~m}$. All the simulations are performed with the FB model.
The processes are simulated first in the outer grid at a constant time step of $0.01 \mathrm{~s}$. Temporal variations of water surface elevations and water velocities are output at $x=150 \mathrm{~m}$. They are then input into the inner grid as boundary conditions, and the simulations are conducted at a time step of $0.005 \mathrm{~s}$. In 


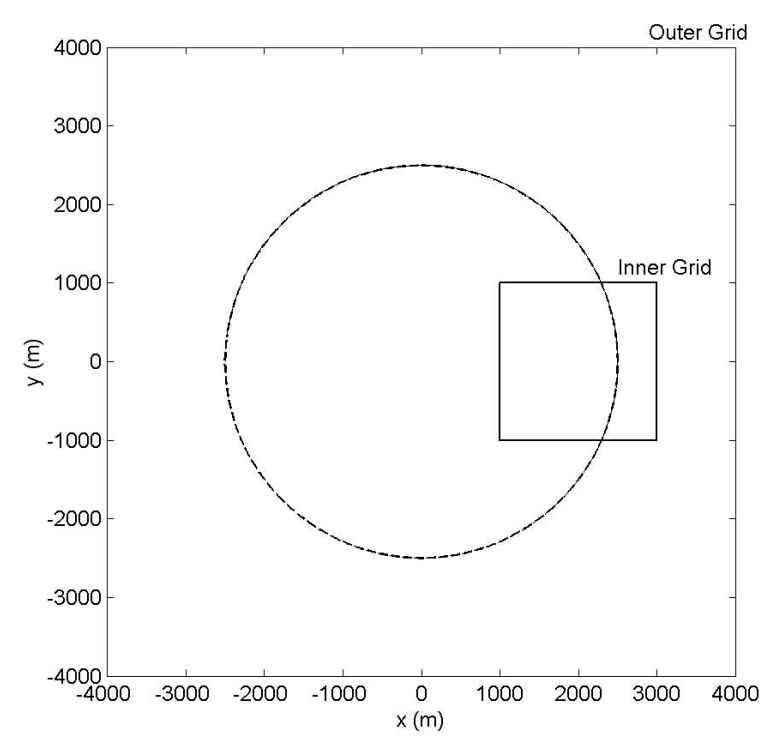

Fig. 8. Computational grids for the simulation of long-wave oscillation in a parabolic basin. The dashed circle denotes the elevation of 0 .

Fig. 5, we compare the time series of water surface elevations at $x=175 \mathrm{~m}$. Good agreement is observed in all cases. The errors in both wave height and phase become bigger for shorter waves, as the effects of numerical dispersion become more significant. Another reason for these errors lies in the interpolation of time series.

\subsection{Wave evolution over a submerged sill}

Beji and Battjies $(1993,1994)$ conducted a series of experiments with regular periodic waves propagating over a submerged sill. A schematic diagram of the experimental setup is given in Fig. 6. The sill has a front and a back incline with slopes of 1:20 and 1:10, respectively, and placed in the still water depth of $0.40 \mathrm{~m}$. Waves are generated by a wave maker near the left end of the flume. Behind the sill, a sloping beach is installed to work as a wave dissipater. Temporal variations of water surface elevations are recorded by the wave gages over the sill. These experiments, and similar ones, have been employed as a classical benchmark to validate nonlinear and dispersive numerical models (e.g. Beji and Battjies, 1994; Gobbi and Kirby, 1999; Lin and Man, 2007).

In the present study, we apply the FB and GB models to the case with a wave period of $2.0 \mathrm{~s}$ and wave height of $2.0 \mathrm{~cm}$. The quasi 1-D flume has a width of $0.5 \mathrm{~m}$. A uniform grid spacing of $0.05 \mathrm{~m}$ is applied along the flume and in the transverse direction. The time step is $0.01 \mathrm{~s}$. Precomputed time series of water surface elevations and water velocities are input along the left boundary. Figure 7 indicates a good agreement between the experimental measurements and numerical simulations. The maximum ratio of wave height to local water depth is 0.31 , measured at Gage 4 over the top of the sill.
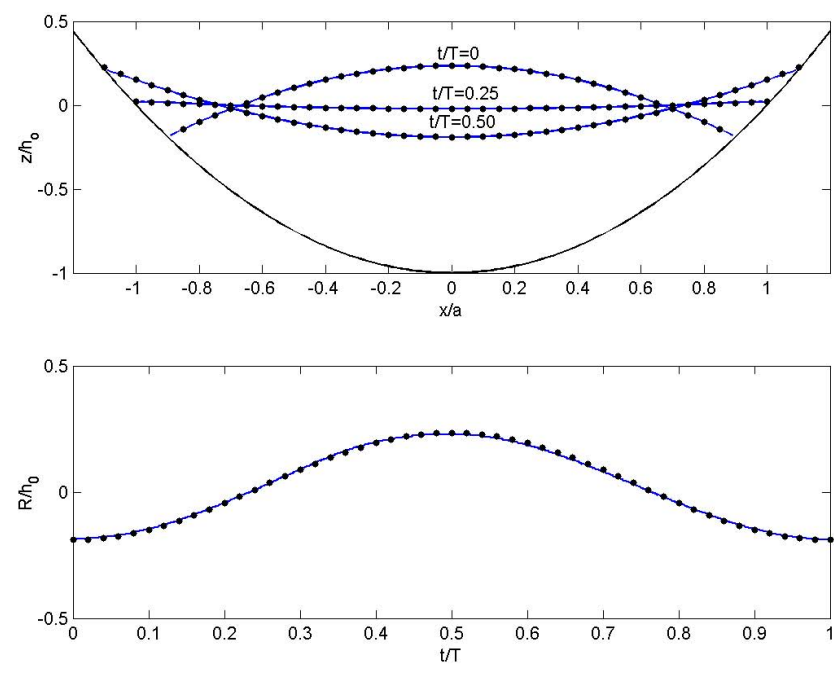

Fig. 9. Comparison between simulations (-) and analytical solution (.) for the long-wave oscillation in a parabolic basin. Upper: water surface profiles; lower: runup.

Simulation results of both models indicate that for such a problem, the weakly nonlinear theory still works accurately.

We note the length scale in the wave tank is extremely small compared with the radius of the Earth. As a result, the grid spacing is at an order of $O\left(10^{-9}\right)$ described in radians of longitude and latitude, which are the quantities employed in the GB model. This may cause overflow during the computations. In order to avoid this problem, we create an "artificial planet" with a radius of $20.626 \mathrm{~km}$, and place the south sidewall of the numerical flume along the equator. The length of $0.1 \mathrm{~m}$ is equivalent to $1.0^{\prime \prime}$ on this planet. The curvature of the Earth's surface and the Coriolis effect are both negligible in this event. Therefore, applying the "artificial planet" may not affect the physical processes.

\subsection{Long-wave oscillation in a parabolic basin}

An analytical solution to the nonlinear shallow water equations was derived by Thacker (1981) for the resonant oscillation of long waves in a parabolic basin. The basin has a cylindrically symmetric bathymetry, described as

$h(r)=h_{o}\left(1-\frac{r^{2}}{a^{2}}\right)$,

where $h_{o}$ is the water depth at the cylindrical axis, $r=$ $\sqrt{x^{2}+y^{2}}$ is the distance between an arbitrary point and the axis, and $a$ is the radius of the circle at zero elevation. The water surface elevation is given as a function of time and location, which reads 


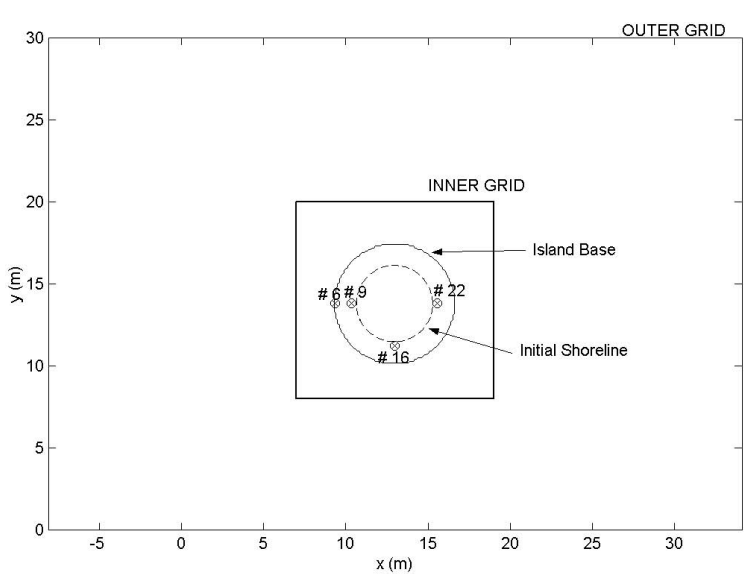

Fig. 10. Numerical wave tank for the experiments with conical island. Dashed circle denotes the original shoreline.

$$
\begin{aligned}
\zeta(r, t) & =h_{o}\left\{\frac{\sqrt{1-A^{2}}}{1-A \cos \omega t}\right. \\
& \left.-1-\frac{r^{2}}{a^{2}}\left[\frac{1-A^{2}}{(1-A \cos \omega t)^{2}}-1\right]\right\},
\end{aligned}
$$

where $\omega=\sqrt{8 g h_{o}} / a$ is the angular frequency, and

$A=\frac{a^{4}-r_{o}^{4}}{a^{4}+r_{o}^{4}}$.

The runup, $R$, is also described as a periodic function,

$R=-h_{o}\left(1-\frac{1-A \cos \omega t}{\sqrt{1-A^{2}}}\right)$.

This solution has been employed by Lynett (2002) to validate the numerical code of COULWAVE. In his study, only results computed without dispersive terms are presented and compared with the analytical solution. In the present study, we observe the simulations with the FB and GB models have a slight phase difference from the analytical solution. It is because the Boussinesq-type models include frequency dispersion, which is not considered in the analytical solution. As a result, the agreement between the models and analytical solution becomes poor after several cycles of oscillation. Here, we only present the simulation results in the first circle.

In the present study, the parameters are set as $h_{o}=1.0 \mathrm{~m}$, $a=2500 \mathrm{~m}$ and $r_{o} / a=0.90$. The configuration of computational grids is depicted in Fig. 8. In the outer grid, the computation is conducted with the GB model at a resolution of $25 \mathrm{~m}$ and a time step of $0.0005 T$, where $T=2 \pi / \omega$ is the period of oscillation. In the inner grid, the FB model is applied with a resolution of $5 \mathrm{~m}$ and a time step of $0.0001 T$. In Fig. 9, we compare the simulations with the analytical solutions for both water surface profiles and runup. The simulation agrees well with the analytical solution. A determination coefficient of 0.9989 is obtained for the time series of runup and drawdown.

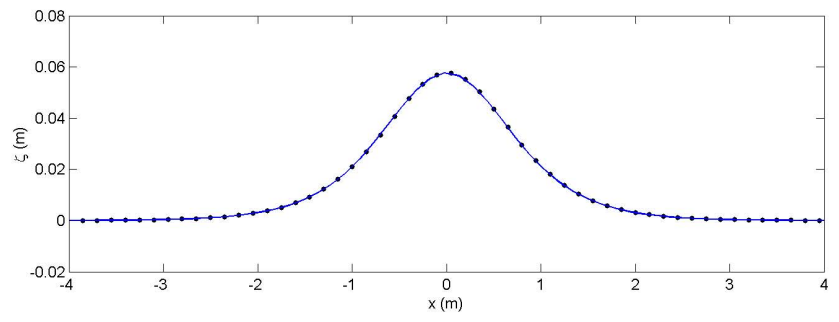

Fig. 11. Water surface profiles of a solitary wave with $0.058 \mathrm{~m}$ wave height propagating in constant water depth of $0.32 \mathrm{~m}$ : profile at $t=0$ (.) compared with that at $t=60 \mathrm{~s}$ shifted leftward in $114.97 \mathrm{~m} \mathrm{(-).}$

\subsection{Runup of solitary waves on a conical island}

Experiments of solitary wave runup on a conical island were first reported by Briggs et al. (1994) and have served as a benchmark in numerous studies for validating wave runup models (e.g. Liu et al., 1995; Kânoğlu and Synolakis, 1998; Titov and Synolakis, 1998; Chen et al., 2000; Lynett et al., 2002; Yamazaki et al., 2009). In this section, we also validate the nested-grid approach by employing these experiments. The initial wave heights are $0.013,0.028$ and $0.058 \mathrm{~m}$ in the still water depth of $0.32 \mathrm{~m}$, or equivalently in nondimensional forms are $A / h=0.041,0.088$ and 0.181 , where $A$ is the initial wave height and $h$ is still water depth. The configuration of the numerical wave tank is given in Fig. 10. A uniform grid spacing of $0.15 \mathrm{~m}$ is applied in both directions of the outer grid. The inner grid has a resolution of $0.05 \mathrm{~m}$.

We first obtain the steady solitary wave forms in 1-D through a trail-and-error method. The initial conditions include the water surface elevations and water velocities approximated through the closed-form empirical equations of Teng (1997). This profile is not an exact solution to the model equations we employ. As a result, the initial wave is unstable and oscillatory trails will develop following the main wave. The main wave has higher wave height and travels faster. After the main wave is fully separated from the trails, it is cut out, multiplied by a coefficient to reach the desired wave height and input into the model as initial conditions for a new run. This procedure is repeated until a steady solitary wave of desired wave height is obtained. In Fig. 11, we compare the profiles of the steady solitary wave of $A / h=0.181$ at $t=0$ and $60 \mathrm{~s}$. The latter has been shifted leftward in $114.97 \mathrm{~m}$, which is the distance the wave has travelled. The wave propagates at a constant speed of $1.916 \mathrm{~m} \mathrm{~s}^{-1}$, which is slightly lower than that estimated in Rayleigh-Boussinesq's theory for finite amplitude solitary waves, i.e., $\sqrt{g(h+A)}$ (e.g. Miles, 1980).

The steady solitary wave profiles and water velocities are uniformly distributed along the $y$-axis in the numerical wave tank to compose initial conditions. In the case of $A / h=0.041$, we employ the GB model in both grids. The nonlinear effects become stronger in the other two events and, therefore, the FB model is applied. In Fig. 12, we 

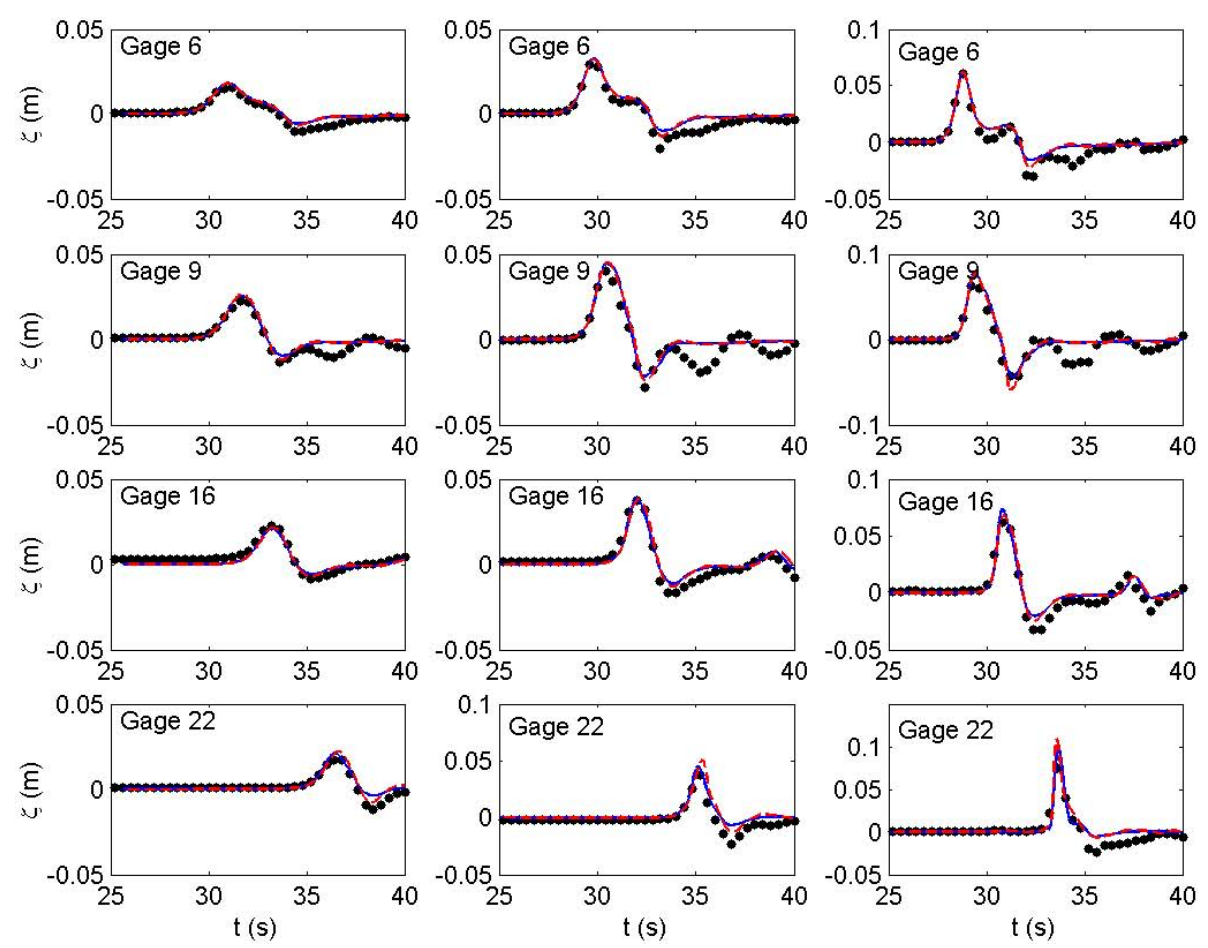

Fig. 12. Time series of water surface displacements in the experiments of solitary wave runup on conical island: measurements (.), simulations in outer grid (-) and inner grid (- -). Initial wave heights are $A / h=0.041,0.088$ and 0.181 in columns from left to right.
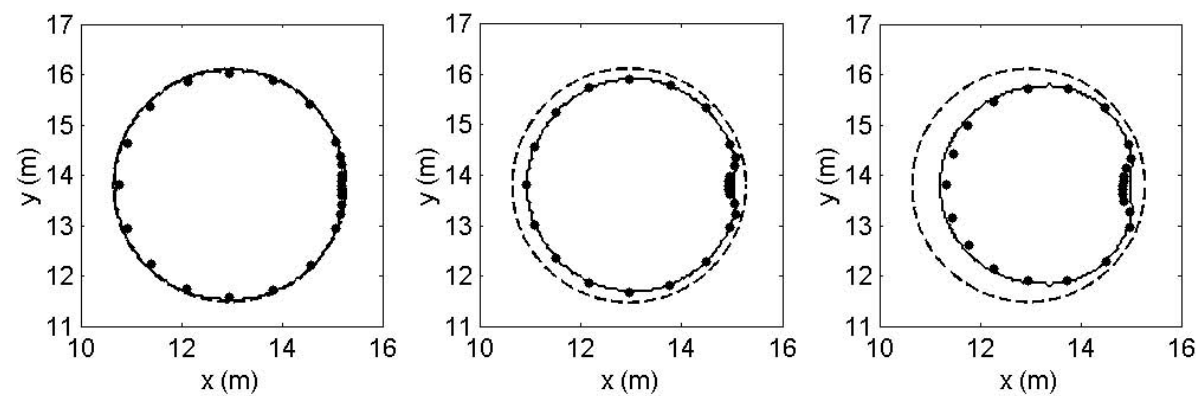

Fig. 13. Maximum inundation on the conical island: measured in experiments (.) and simulated in inner grid (一). Dashed circles depict the initial shorelines. Initial wave heights are $A / h=0.041,0.088$ and 0.181 in columns from left to right.

compare the time series of water surface elevations simulated in both grids with those measured at four selected wave gages. The good agreement between inner and outer grids shows the accuracy of the nesting scheme. In the weakly nonlinear case of $A / h=0.041$, the numerical model has very good agreement with the measurements. In the case of $A / h=0.181$, wave breaks on the lee slope of the island (Liu et al., 1995). At gage 22, the model predicts a maximum water surface elevation of $0.109 \mathrm{~m}$ in the inner grid, nearly $20 \%$ higher than that measured in the experiment. The reason may be that energy dissipation due to wave breaking is underestimated. We also note that the error is smaller in the outer grid, where we predict a maximum water surface elevation of $0.097 \mathrm{~m}$ at gage 22 , which is $6.5 \%$ higher than measurement.
Numerical dissipation in coarse resolution may be a reason for this phenomenon. The measured maximum inundations on the island are also compared with those predicted in the inner grid in Fig. 13. In general, reasonably good agreement is observed in all the comparisons.

\subsection{The 2006 Kuril Islands Tsunami}

At 11:14:16 UTC on 15 November 2006, an earthquake of Mw 8.3 generated a tsunami near the Kuril Islands. Time series of water surface elevations have been recorded at DART ("Deep-ocean Assessment and Reporting of Tsunamis") sensors deployed in the Pacific Ocean and several tide stations around the basin. This event is a standard historical case for 


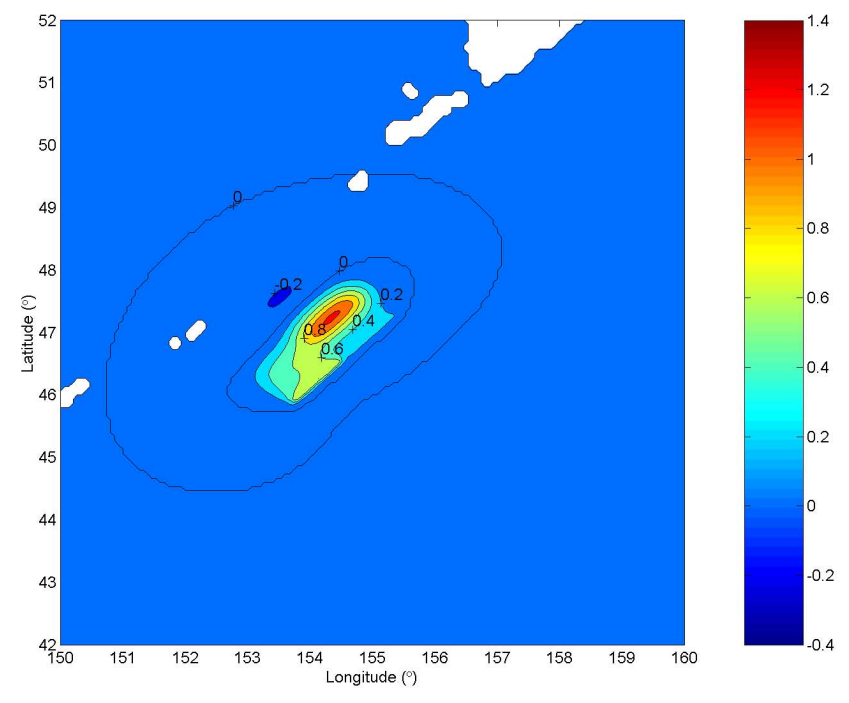

Fig. 14. Tsunami source (water surface displacement in metres) of the 15 November 2006 event near Kuril Islands.

model validation during the development of NOAA's tsunami forecast and warning system, SIFT ("Short-term Inundation Forecasting for Tsunamis"). In the present study, we employ this event to validate the nested-grid Boussinesq-type approach. MOST is also applied in the same grids as a reference.

The initial distribution of water surface elevations estimated through the inverse algorithm of SIFT is given in Fig. 14. This algorithm depends on the real-time measurements of DART sensors, and constrains the tsunami source by fitting these measurements to a linear combination of precomputed tsunami source functions (Tang et al., 2009). A tsunami source function is defined as the time series of water surface displacements and water velocities in an ocean basin caused by a unit earthquake source, which has a dimension of $100 \times 50 \mathrm{~km}^{2}$, and a slip value of $1 \mathrm{~m}$, equivalent to a moment magnitude of 7.5 (Gica et al., 2008). The tsunami source functions are computed with MOST at a resolution of $4^{\prime}$ in most areas. Studies suggest that at this resolution, the magnitude of numerical dispersion of MOST approximates that of the physical frequency dispersion, making it applicable to dispersive waves (Burwell et al., 2007).

By applying the GB model, we simulate the tsunami propagation in the North Pacific basin. To be consistent with SIFT, a resolution of $4^{\prime}$ is applied in this domain. Bathymetric and topographic data are derived from the ETOPO2 two-minute global relief database. Within this domain, time series of computed water surface elevations are output at locations of DART buoys 21414, 46411, 46412, 46419 and 51 407. Surrounding the main Hawaiian Islands, we construct Grid A at a resolution of $30^{\prime \prime}$. The computation is further zoomed into smaller domains in Grids B and C, which cover the vicinity of Hilo Bay area at resolutions of 6 " and $1^{\prime \prime}$, respectively. The weakly nonlinear GB model is applied to Grids A and B, while in Grid C, the fully nonlinear FB model is employed. The high-resolution bathymetric and topographic data are derived from the digital elevation models (DEMs) developed by the National Geophysical Data Center. Time series of water surface elevations is also output from Grid C at the location of the tide station in Hilo Bay. The computational domains, as well as the locations of DART buoys and tide station, are presented in Fig. 15.

We first check the accuracy of nesting scheme by outputing the time series of water surface elevations from Grids A, $\mathrm{B}$ and $\mathrm{C}$ at a numerical wave gage near the entrance of Hilo Bay $\left(19.75^{\circ} \mathrm{N}, 155.07^{\circ} \mathrm{W}\right)$. The three time series are compared in Fig. 16. For the first two peaks, the agreement is nearly perfect between Grids B and C. In Fig. 17, we compare the computational results of the Boussinesq-type models and MOST with real-time measurements at DART sensors and the tide station. Very good agreement is observed for the leading waves in the deep ocean. In the trailing waves, the two numerical approaches agree with each other though both deviate from the measurements. The poor agreement between numerical results and measurements in trailing waves may be due to the inaccuracy of initial conditions. At the Hilo Bay tide station, the two numerical approaches deviate from each other in the trailing waves. This is a sign of mismatch between the numerical dispersion of MOST and the frequency dispersion included in FB. During this event, coastal runup was not measured in the Hilo Bay area. Therefore, no verification of runup is investigated.

\section{A potential tsunami from La Palma Island}

Urgeles et al. (1999) reported that a landslide with a volume of $650 \mathrm{~km}^{3}$ had happened west of La Palma Island 0.8 to 1 million years ago. A landslide of this scale can generate a mega tsunami which may propagate across the Atlantic Ocean and flood the US east coast. Ward and Day (2001) indicated that the future eruption of the Cumbre Vieja volcano on La Palma Island will likely trigger a failure on its west flank. By assuming a debris volume of $500 \mathrm{~km}^{3}$, they predicted the potential landslide and tsunami will result in 20-25 m high waves offshore of the state of Florida. In their study, the mathematical analysis was conducted through a linear theory and the landslide behaviour was approximated as deformable blocks (Ward, 2001). Gisler et al. (2006) revisited this problem with a numerical code, SAGE, which solves the three-dimensional (3-D) Navier-Stokes equations. In the 3-D scenario, they employed a landslide volume of $375 \mathrm{~km}^{3}$. Based on this scenario, Løvholt et al. (2008) simulated the oceanic propagation of the potential tsunami with a Boussinesq model and predicted a maximum water surface elevation of $9.6 \mathrm{~m}$ offshore of the US east coast.

Studies indicate that for the waves generated by an underwater or sub-aerial landslide, the wave heights are sensitive to many factors such as the volume, density, viscosity and 


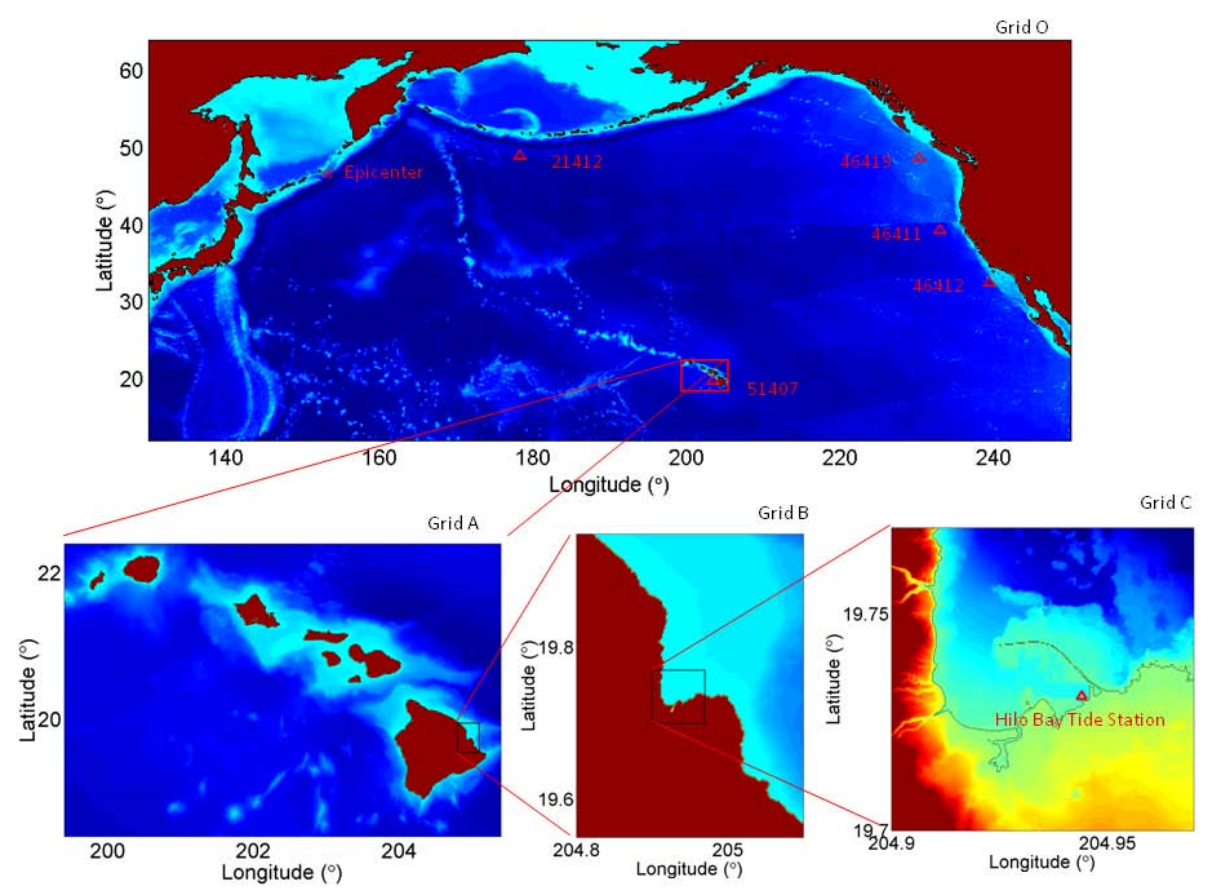

Fig. 15. Computational grids for the simulation of the 2006 Kuril Islands tsunami.

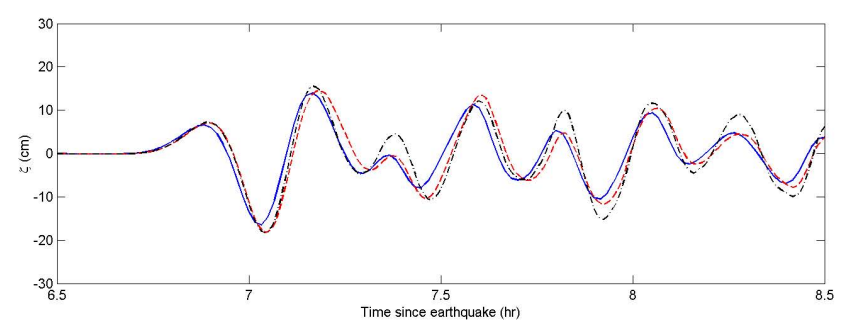

Fig. 16. Time series of water surface elevations output at a numerical wave gage $\left(19.75^{\circ} \mathrm{N}, 155.07^{\circ} \mathrm{W}\right)$ from Grids $\mathrm{A}(-), \mathrm{B}(--)$ and $\mathrm{C}(-$.$) .$

initial position of the debris, as well as the slope angle over which the debris flows downslope (e.g. Fritz et al., 2004; Grilli and Watts, 2005; Watts et al., 2005). There are still controversies regarding the properties of the potential landslide on La Palma Island. For instance, Abadie et al. (2008) indicated that the volume of major collapse on the west flank may fall within a range of $108-130 \mathrm{~km}^{3}$, if the volcanic eruption is considered as the only triggering mechanism. This estimation is far smaller than that by Ward and Day (2001). We would like to stress that, so far, human history has not seen such a gigantic landslide on this island. Such an event may have a very long return period of probably thousands or millions of years.

In this section, we apply the nested-grid Boussinesq-type approach to estimate the potential tsunami impact on the US east coast due to landslide on La Palma Island. Our objective is to show a possible application of the newly developed numerical package. Instead of going deep into the landslide and tsunami generation mechanism, we construct a hypothetical tsunami based on the numerical scenario of Cth31 in Gisler et al.'s (2006) study.

\subsection{Hypothetical tsunami}

Gisler et al. (2006) simulated the coupled process of landslide motion and tsunami generation in a cylindrical symmetric frame in scenario Cth31. A snapshot of water surface profile at $300 \mathrm{~s}$ is presented by Løvholt et al. (2008) (Fig. 3 in this reference), and used as the initial condition for model comparisons. The wave has a leading peak of approximately $250 \mathrm{~m}$ located nearly $55 \mathrm{~km}$ from the cylindrical center, and a trough of $450 \mathrm{~m}$, separated from the peak by about $20 \mathrm{~km}$. Løvholt et al. (2008) proved that since $300 \mathrm{~s}$, the evolution of the first wave can be accurately predicted with the Boussinesq models, though the landslide is still in motion, but is not considered. This may be due to the fact that the first wave has already passed the moving landslide. In the present study, this profile is simplified as a leading-peak $\mathrm{N}$-wave described as

$\zeta(x)=A_{1} e^{-k_{1} \frac{\left(x-x_{1}\right)^{2}}{\left(x_{1}-x_{2}\right)^{2}}}-A_{2} e^{-k_{2} \frac{\left(x-x_{2}\right)^{2}}{\left(x_{1}-x_{2}\right)^{2}}}$,

where $A_{1}=250.0 \mathrm{~m}, A_{2}=442.0 \mathrm{~m}, x_{1}=56 \mathrm{~km}, x_{2}=35 \mathrm{~km}$, $k_{1}=5.0$ and $k_{2}=7.0$. In Fig. 18, we present the water surface profile depicted with Eq. (7) and that in scenario Cth31. For the leading peak, Eq. (7) approximates the numerical result. The leading peak in the initial profile is of primary importance to the tsunami impact on the US east coast. The tails 

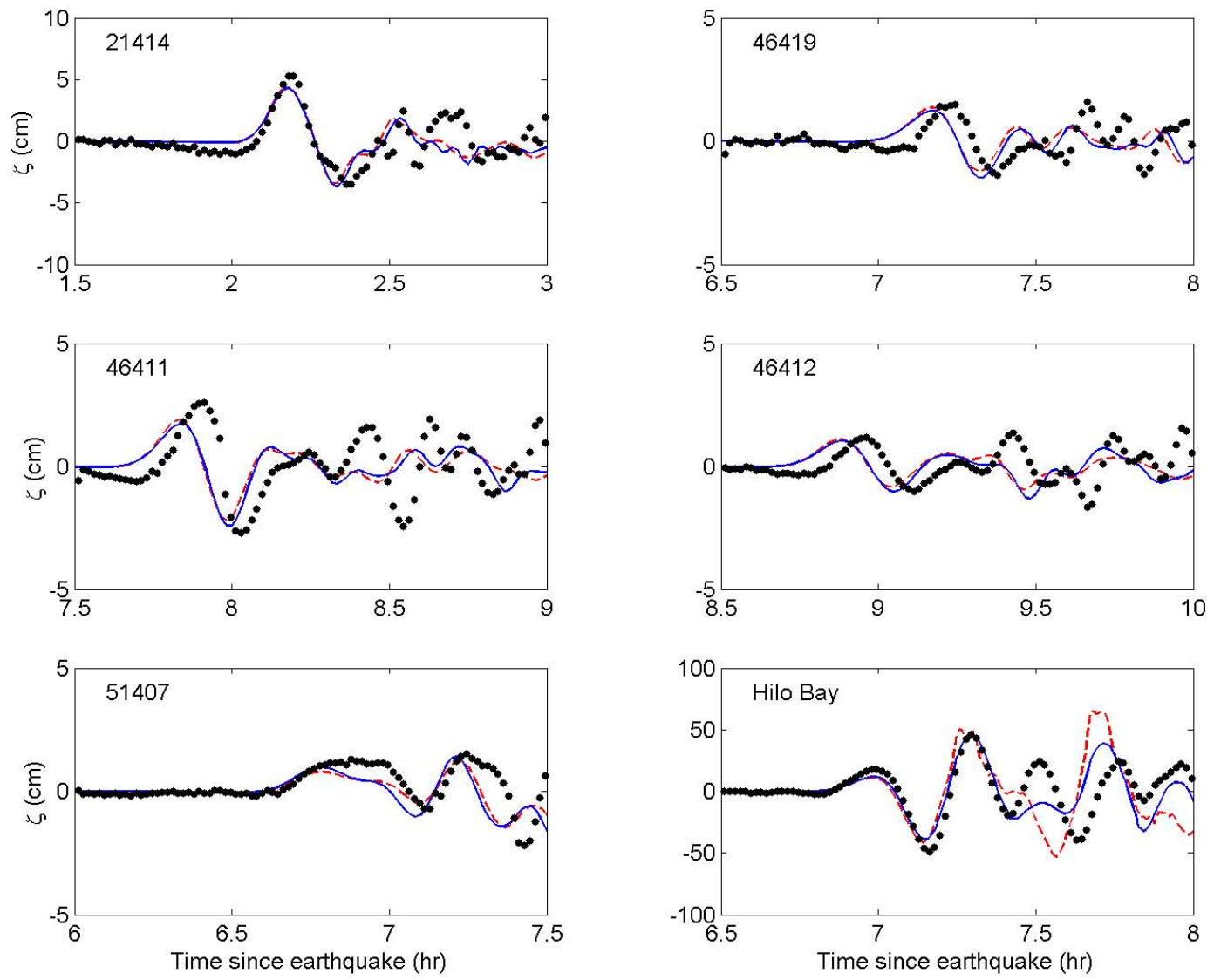

Fig. 17. Time series of water surface elevations at DART sensors and Hilo Bay tide station in the 2006 Kuril Islands tsunami event: Boussinesq (-), MOST (- -) and measurements (.).

predicted by Gisler et al. (2006) are smoothed out as they may cause huge runup on the Canary Islands and make the numerical model unstable. In fact, the tails will mostly vanish in the transatlantic propagation due to frequency dispersion. The wave field in the horizontal 2-D plane is generated by rotating this profile clockwise from south to north around a vertical axis going through $\left(28.7^{\circ} \mathrm{N}, 17.85^{\circ} \mathrm{W}\right)$, considering that the potential landslide is likely to be limited to the west flank. Through a simple geometric calculation, we estimate the landslide volume as being $365 \mathrm{~km}^{3}$ if the transect of landslide is spread for $180^{\circ}$ around the cylindrical axis. Under this wave, the water velocities are assumed to point outward from the axis. The magnitudes of depth-averaged water velocities are estimated as $|\overline{\boldsymbol{u}}|=\zeta \sqrt{g / H}$. The reference water velocities $\boldsymbol{u}_{\alpha}$ in geographical coordinates are computed through the following equations

$$
\begin{aligned}
u_{\alpha}= & \bar{u}+\frac{1}{R^{2} \cos ^{2} \theta}\left[\frac{1}{6}\left(\zeta^{2}-\zeta h+h^{2}\right)-\frac{z_{\alpha}^{2}}{2}\right] \\
& \cdot\left[\frac{\partial^{2} \bar{u}}{\partial \phi^{2}}+\frac{\partial^{2}}{\partial \phi \partial \theta}(\bar{v} \cos \theta)\right]
\end{aligned}
$$

$$
\begin{aligned}
+ & \frac{1}{R^{2} \cos ^{2} \theta}\left[\frac{1}{2}(\zeta-h)-z_{\alpha}\right] \\
& +\left[\frac{\partial^{2}}{\partial \phi^{2}}(h \bar{u})+\frac{\partial^{2}}{\partial \phi \partial \theta}(h \bar{v} \cos \theta)\right], \\
v_{\alpha}= & \bar{v}+\frac{1}{R^{2} \cos ^{2} \theta}\left[\frac{1}{6}\left(\zeta^{2}-\zeta h+h^{2}\right)-\frac{z_{\alpha}^{2}}{2}\right] \\
& +\left\{\left[\frac{\partial^{2} \bar{u}}{\partial \phi \partial \theta}+\frac{\partial^{2}}{\partial \theta^{2}}(\bar{v} \cos \theta)\right] \cos \theta\right. \\
+ & {\left.\left[\frac{\partial \bar{u}}{\partial \phi}+\frac{\partial}{\partial \theta}(\bar{v} \cos \theta)\right] \sin \theta\right\} } \\
+ & \frac{1}{R^{2} \cos ^{2} \theta}\left[\frac{1}{2}(\zeta-h)-z_{\alpha}\right] \\
& +\left\{\frac{\partial^{2}}{\partial \phi \partial \theta}(h \bar{u})+\frac{\partial^{2}}{\partial \theta^{2}}(h \bar{v} \cos \theta)\right] \cos \theta \\
+ & {\left[\frac{\partial}{\partial \phi}\left(h \bar{u}+\frac{\partial}{\partial \theta}(h \bar{v} \cos \theta)\right] \sin \theta\right\}, }
\end{aligned}
$$

where $R$ is the radius of the Earth and $z_{\alpha}=-0.531 h$ $+0.469 \zeta$ is the reference level within the water column. 


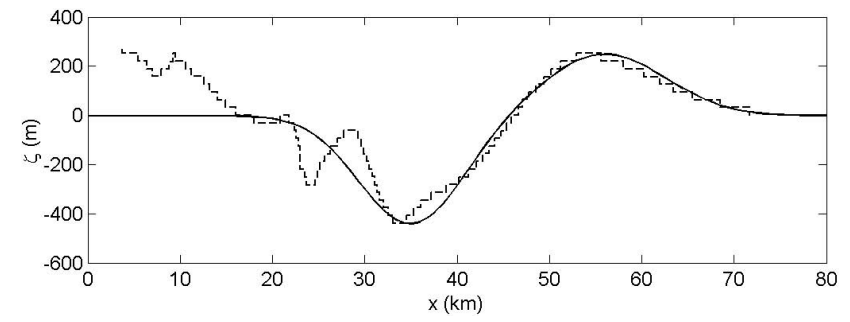

Fig. 18. Water surface profile depicted with Eq. (7) (-) and that in Gisler et al.'s (2006) numerical scenario Cth31 (- -), digitalized from Løvholt et al.'s (2008) Fig. 3.

It is worthwhile to mention that in all the studies of Ward and Day (2001), Gisler et al. (2006) and Abadie et al. (2008), the initial wave fields have a directivity towards the southwest. Løvholt et al. (2008) also show, in the early stage of propagation, the highest wave height is observed along a transect which has an angle of approximately $-20^{\circ}$ from the westward direction. This directivity is not adopted in the present study. As a result, there is more wave energy projected towards the US east coast, where the tsunami impact may be overestimated.

\subsection{Oceanic propagation}

The oceanic propagation is simulated with the GB model. Bottom friction is not included in this process. At first, a grid refinement test is performed near the island using resolutions of $0.5^{\prime}, 1.0^{\prime}$ and $2.0^{\prime}$. Bathymetric data are derived from the ETOPO2 database. Linear interpolation is applied to generate data at higher resolutions. Figure 19 shows the water surface profiles along $28.7^{\circ} \mathrm{N}$ latitude at $t=25 \mathrm{~min}$, predicted at the three different resolutions. The coefficient of determination between the $0.5^{\prime}$ and $1.0^{\prime}$ simulations is approximately 1.0 over the first two waves. Between the $0.5^{\prime}$ and $2.0^{\prime}$ simulations, we have a slightly poorer agreement with a determination coefficient of 0.9985 . For the shorter trailing waves, the deviation becomes bigger.

Near the source of a landslide-generated tsunami, wavelengths are short and, therefore, higher resolution is required. As waves propagate outward from the source, they become longer due to frequency dispersion, thus, larger grid spacings are adequate. In order to accurately model the shorter waves at a reasonable computation expense, we split the transatlantic propagation into three stages. At first, we employ a resolution of $0.5^{\prime}$ in the vicinity of La Palma Island. The domain covers a range of $23^{\circ} \mathrm{W}-15^{\circ} \mathrm{W}$ in longitudes and $25^{\circ} \mathrm{N}-33^{\circ} \mathrm{N}$ in latitudes. Fully reflective walls are installed along the four boundaries. Before the waves reach the reflective walls, the computed $\zeta$ and $\boldsymbol{u}_{\alpha}$ at $t=20 \mathrm{~min}$ are transferred into an enlarged domain measuring $30^{\circ} \mathrm{W}-10^{\circ} \mathrm{W}$ in longitudes and $20^{\circ} \mathrm{N}-38^{\circ} \mathrm{N}$ in latitudes at a resolution of $1^{\prime}$. Fully reflective boundary conditions are also applied in this grid. Simulation results output from this domain at $t=70 \mathrm{~min}$

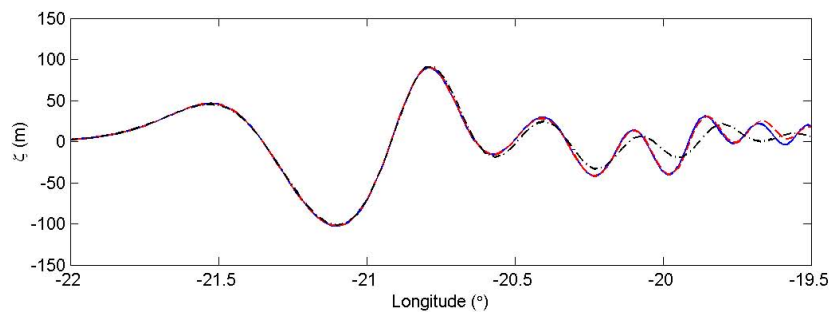

Fig. 19. Water surface profiles along $28.7^{\circ} \mathrm{N}$ longitude at $t=25$ min, simulated at resolutions of $0.5^{\prime}(-), 1.0^{\prime}(--)$ and $2.0^{\prime}(-$.).

are transferred into a new grid for further computation. In the third stage, the computational grid has a resolution of $2^{\prime}$ and covers most of the North Atlantic basin, measuring $85^{\circ} \mathrm{W}-$ $0^{\circ}$ in longitudes and $15^{\circ} \mathrm{N}-50^{\circ} \mathrm{N}$ in latitudes. Sponge layers are placed along the north and south boundaries. The bathymetric and topographic data in these grids are derived from the ETOPO2 database.

The simulation in a following stage starts $5 \mathrm{~min}$ before it stops in the proceeding stage. In other words, there is a $5 \mathrm{~min}$ overlap between any two consecutive stages. By comparing the water surface elevations between the two consecutive stages at the same time, we can check the accuracy of grid resolutions. The determination coefficients are calculated to be 0.9964 between the first and the second stages at $t=25 \mathrm{~min}$, and 0.9817 between the second and the third stages at $t=75 \mathrm{~min}$.

A few snapshots of the water surface near La Palma Island are presented in Fig. 20. Soon after the simulation starts, the initial $\mathrm{N}$-wave evolves into a leading crest and a train of shorter oscillatory waves. Due to frequency dispersion and geometric spreading, the heights of the leading waves decrease quickly. Right before the wave system reaches the west brim of deep ocean, the leading peak has a height of $2.2 \mathrm{~m}$ above still water level and the length of the first wave is $220 \mathrm{~km}$, measured along the $28.7^{\circ} \mathrm{N}$ latitude. The trailing waves are higher and shorter. The first trailing wave has a peak-to-trough height of $12.8 \mathrm{~m}$, and a length of $125 \mathrm{~km}$. Our observation on the wavelengths is consistent with that reported by Løvholt et al. (2008), which indicated that the typical wavelengths range between 120 to $250 \mathrm{~km}$ for the leading peak, and 50 to $100 \mathrm{~km}$ for the trails, and both increase with travelling distance.

In Fig. 21, we present the maximum water surface elevations in the North Atlantic basin. These data are from the simulations described in this section, except near the US east coast, where the data are output from the A-level nested grids at a resolution of $0.5^{\prime}$ and the seabed friction is included. Clear directivity is observed in this figure. As reported in some studies (e.g. Titov et al., 2005; Grilli et al., 2007), the directivity of tsunami propagation is a result of combined effects of tsunami source configuration and bathymetric features. Shown in Fig. 21, a beam of high wave energy is projected westwards to the states of South Carolina, Georgia and 

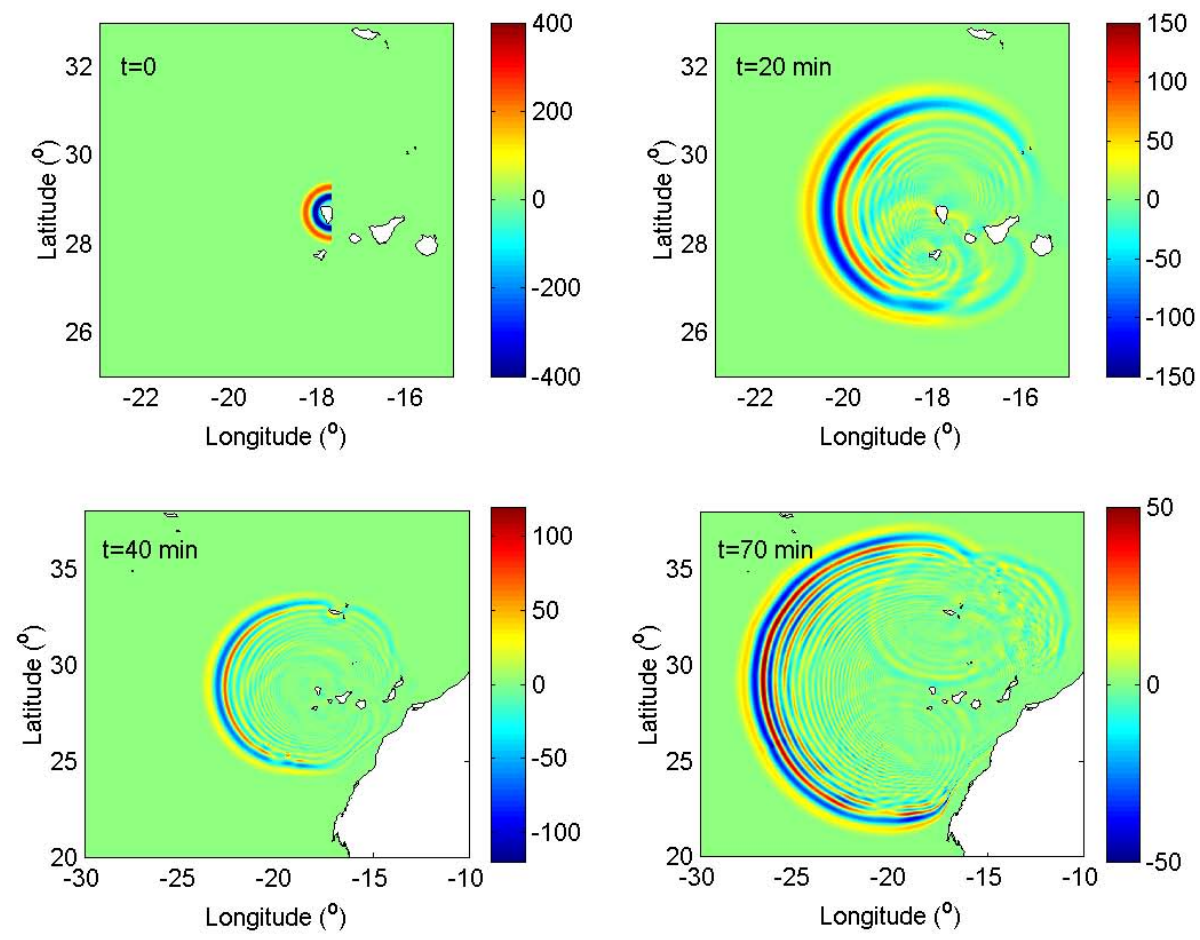

Fig. 20. Snapshots of the water surface in the vicinity of La Palma Island. Due to initial condition, more wave energy is projected westwards compared with the studies by Løvholt et al. (2008).

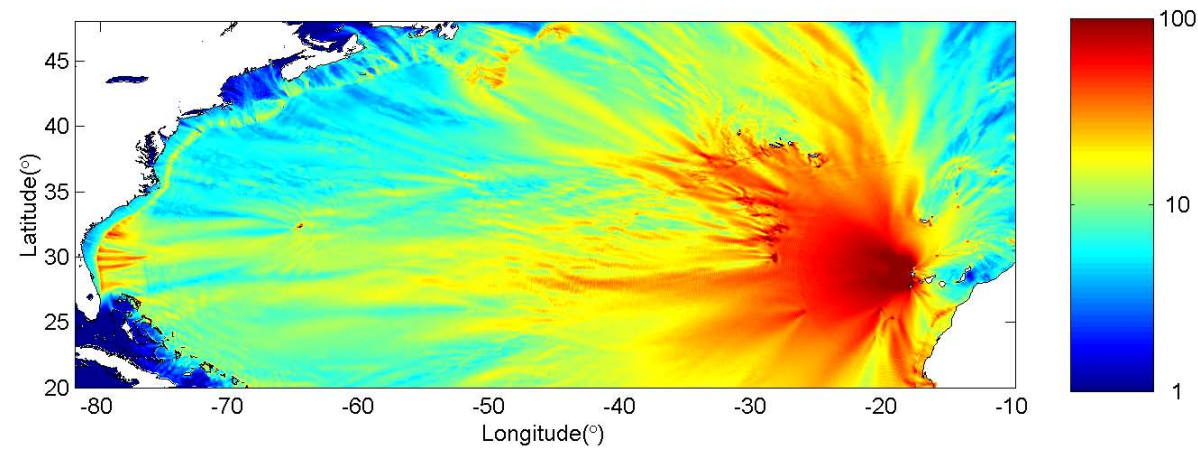

Fig. 21. Maximum water surface elevations $(\mathrm{m})$ in the North Atlantic basin. Due to initial condition, more wave energy is projected westwards compared with the studies by Løvholt et al. (2008).

Florida. This is consistent with the assumption we made on the tsunami source, i.e., the initial wave field is symmetric about the $28.7^{\circ} \mathrm{N}$ latitude.

According to the simulation, waves propagate into the continental shelf east of Newfoundland Island after $4.5 \mathrm{~h}$ since the tsunami was generated. Later, this tsunami approaches New England at approximately $6.0 \mathrm{~h}$, the Carolinas at $7.0 \mathrm{~h}$ and Florida at $8.0 \mathrm{~h}$.

\subsection{Shoaling and runup}

After the waves propagate into nearshore shallow water, wavelengths become shorter due to shoaling effects and, therefore, higher resolution is desired. The modelling of runup and inundation requires even higher resolutions. Along the US east coast, we construct the computational grids at three levels: A, B and C. The grids are named as A1, B11, C11, etc. The domains of A-level grids cover the entire continental shelf east of the US and part of the deep ocean. A uniform spacing of $30^{\prime \prime}$ is applied. The bathymetric and topographic data are interpolated from ETOPO2. The B-level grids extend for $60-120 \mathrm{~km}$ offshore from dry land, and have resolutions of 3-4" $(\sim 90 \mathrm{~m})$ depending on latitudes. The Clevel grids cover several coastal communities at resolutions of $0.5-0.6^{\prime \prime}(\sim 15 \mathrm{~m})$. Bathymetric and topographic data are 
Table 1. Computational Grids along the US east coast.

\begin{tabular}{|c|c|c|c|c|c|c|c|c|}
\hline \multirow[t]{2}{*}{ Grids } & \multirow[t]{2}{*}{ Models } & \multicolumn{2}{|c|}{ Spacing } & \multicolumn{4}{|c|}{ Boundaries } & \multirow[t]{2}{*}{ Note } \\
\hline & & $\Delta \phi$ & $\Delta \theta$ & West & East & South & North & \\
\hline A1 & GB & $30^{\prime \prime}$ & $30^{\prime \prime}$ & $-78.0^{\circ}$ & $-64.0^{\circ}$ & $36.0^{\circ}$ & $46^{\circ}$ & \\
\hline A2 & GB & $30^{\prime \prime}$ & $30^{\prime \prime}$ & $-83.0^{\circ}$ & $-73.0^{\circ}$ & $24.0^{\circ}$ & $36.0^{\circ}$ & \\
\hline B11 & FB & $4^{\prime \prime}$ & $3^{\prime \prime}$ & $-72.6^{\circ}$ & $-71.5^{\circ}$ & $40.6^{\circ}$ & $41.4^{\circ}$ & \\
\hline B12 & FB & $4^{\prime \prime}$ & $3^{\prime \prime}$ & $-75.5^{\circ}$ & $-74.8^{\circ}$ & $37.8^{\circ}$ & $38.8^{\circ}$ & \\
\hline $\mathrm{B} 13$ & FB & $4^{\prime \prime}$ & $3^{\prime \prime}$ & $-76.5^{\circ}$ & $-75.5^{\circ}$ & $36.5^{\circ}$ & $37.3^{\circ}$ & \\
\hline B21 & FB & $3^{\prime \prime}$ & $3^{\prime \prime}$ & $-79.2^{\circ}$ & $-78.4^{\circ}$ & $33.25^{\circ}$ & $33.95^{\circ}$ & \\
\hline B22 & FB & $3^{\prime \prime}$ & $3^{\prime \prime}$ & $-81.3^{\circ}$ & $-80.4^{\circ}$ & $31.5^{\circ}$ & $32.4^{\circ}$ & \\
\hline B23 & FB & $3^{\prime \prime}$ & $3^{\prime \prime}$ & $-81.3^{\circ}$ & $-80.5^{\circ}$ & $28.9^{\circ}$ & $29.7^{\circ}$ & \\
\hline $\mathrm{C} 11$ & FB & $0.6^{\prime \prime}$ & $0.5^{\prime \prime}$ & $-72.0^{\circ}$ & $-71.8^{\circ}$ & $40.975^{\circ}$ & $41.125^{\circ}$ & Montauk, NY \\
\hline $\mathrm{C} 12$ & FB & $0.6^{\prime \prime}$ & $0.5^{\prime \prime}$ & $-75.15^{\circ}$ & $-75.0^{\circ}$ & $38.3^{\circ}$ & $38.45^{\circ}$ & Ocean City, MD \\
\hline $\mathrm{C} 13$ & FB & $0.6^{\prime \prime}$ & $0.5^{\prime \prime}$ & $-76.05^{\circ}$ & $-75.9^{\circ}$ & $36.75^{\circ}$ & $36.95^{\circ}$ & Virginia Beach, VI \\
\hline $\mathrm{C} 21$ & FB & $0.6^{\prime \prime}$ & $0.5^{\prime \prime}$ & $-78.96^{\circ}$ & $-78.78^{\circ}$ & $33.61^{\circ}$ & $33.76^{\circ}$ & Myrtle Beach, SC \\
\hline $\mathrm{C} 22$ & FB & $0.6^{\prime \prime}$ & $0.5^{\prime \prime}$ & $-81.0^{\circ}$ & $-80.8^{\circ}$ & $31.905^{\circ}$ & $32.08^{\circ}$ & Savannah, GA \\
\hline $\mathrm{C} 23$ & FB & $0.6^{\prime \prime}$ & $0.5^{\prime \prime}$ & $-81.055^{\circ}$ & $-80.88^{\circ}$ & $29.15^{\circ}$ & $29.3^{\circ}$ & Daytona Beach, FL \\
\hline
\end{tabular}

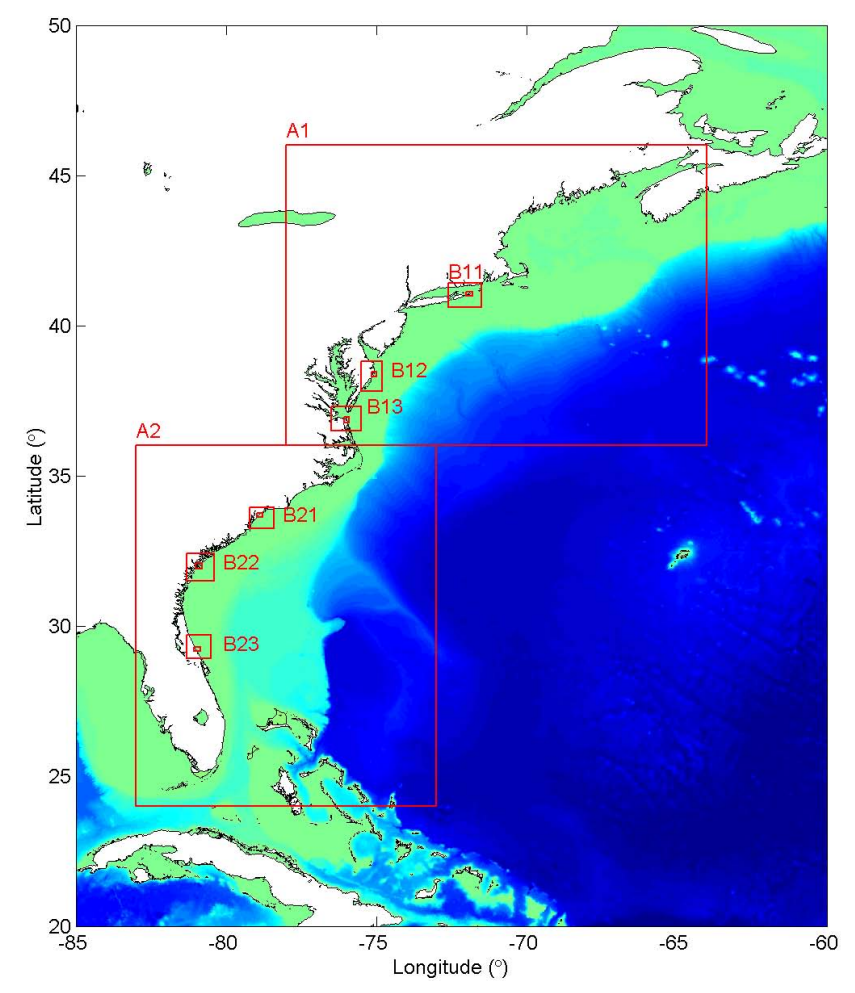

Fig. 22. Computational grids along the US east coast. The titles of $\mathrm{C}$-level grids adopt the numbers from those nesting on B-level, but not marked in this figure.

derived from the high-resolution DEMs. The details of grids are summarized in Table 1 and the domains are plotted in Fig. 22. A constant Manning's roughness coefficient of 0.03 is employed in all the nested grids to approximate the effect of seabed friction.
Shown in Fig. 23 are the maximum water surface elevations offshore the US east coast. Due to shoaling effects, the waves become very high along the edge of the continental shelf. In most sections, the highest water surface elevation exceeds $15 \mathrm{~m}$. The wave heights decay quickly over the continental shelf because of the seabed friction. The runups along the US east coast are also shown in this figure. As most coastal communities are situated on low elevations, they may be severely flooded. Note that in some areas, the runups are significantly lower than those in their neighbours. This does not necessarily mean that these areas experience less severe impact. In these areas the tsunami first overtops some lowlying terrains and then causes runup on the slopes behind.

We would like to stress that the runups presented in Fig. 23 are computed with the weakly nonlinear model at a resolution of $30^{\prime \prime}$. Considerable numerical errors may be present in these results. The nearshore propagation and runup are also simulated with the FB model in B- and C-level grids. The maximum runups in six selected sites are presented in Table 2. The very high runups can be explained by the huge volume of landslide, as well as the assumed directivity of initial waves. In general, the computations in C-level grids yield higher runups. The maximum error is $17.1 \%$, observed between grids B21 and C21 (Myrtle Beach, SC). In Fig. 24, we plot the flooded area in Myrtle Beach predicted in both grids. Surprisingly, the two grids are very consistent. This observation is also valid in most other areas. One reason for the errors in computed runups is that runup is more sensitive to topography. The high-elevation grid node, where the maximum runup is measured, may be missed in a low-resolution grid. 

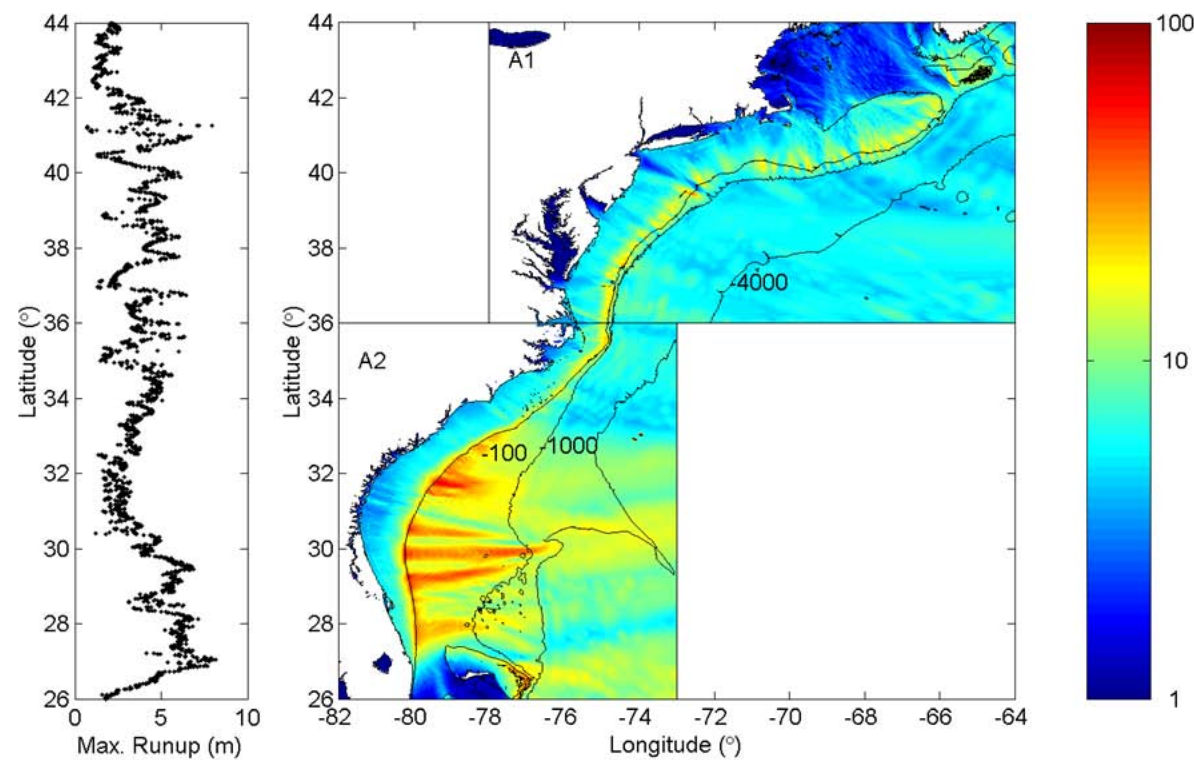

Fig. 23. Maximum water surface elevations (m) near the US and maximum runup on the coast. The solid lines in ocean indicate depths of 4000, 1000 and $100 \mathrm{~m}$.

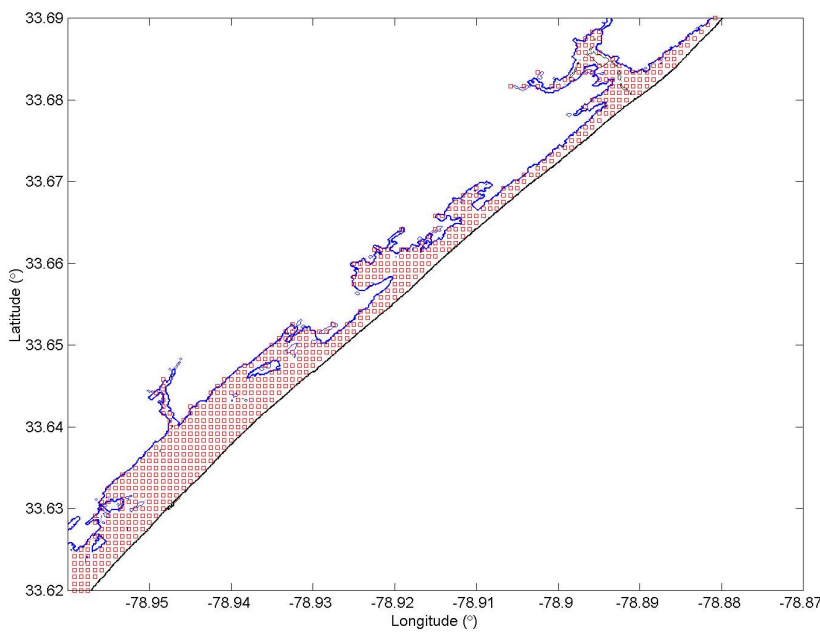

Fig. 24. Tsunami flooding in Myrtle Beach, SC: wet nodes predicted in grid B21 ( $\square$ ) and maximum inundation computed in grid C21 (-).

\subsection{Effect of seabed friction}

The US east coat confronts a continental shelf which measures nearly $100 \mathrm{~km}$ wide, with water depth mostly less than $50 \mathrm{~m}$. While propagating in shallow water, a great amount of wave energy can be dissipated by the seabed friction. In the nearshore grids, we employ a Manning's coefficient of 0.03 . This value is typical for coastal waters (Bryant, 2001). Over the dry land covered by vegetation and structures, applying this value may underestimate the bottom friction forces. On the other hand, the inundating distance is usually shorter than
Table 2. Maximum runups on selected sites along the US east coast.

\begin{tabular}{lcrr}
\hline Sites & \multicolumn{3}{c}{ Max. Runup } \\
\cline { 2 - 4 } & B-level (m) & C-level (m) & Error (\%) \\
\hline Montauk, NY & 9.30 & 10.15 & 8.4 \\
Ocean City, MD & 4.80 & 5.60 & 14.3 \\
Virginia Beach, VI & 5.85 & 6.86 & 14.7 \\
Myrtle Beach, SC & 4.26 & 5.14 & 17.1 \\
Savannah, GA & 3.42 & 3.60 & 5.0 \\
Daytona Beach, FL & 6.89 & 7.67 & 10.1 \\
\hline
\end{tabular}

that of nearshore propagation, the smaller friction coefficient on beaches may not affect the predicted tsunami impact too much. Some studies also suggest that the runup and inundation are indeed not sensitive to the roughness coefficient on steep slopes (e.g. Zelt, 1991; Tang et al., 2009).

In order to show the effect of seabed friction, we also set the Manning's coefficient to 0 and rerun the simulations in Grids A1 and A2 with the GB model. Figure 25 plots the differences in the computed maximum water surface elevations as a percent ratio to the non-friction results. The maximum water surface elevations may be overestimated in some nearshore areas as a result of neglecting the energy dissipation due to wave breaking. Figure 25 shows before the waves approach the shorelines, the water surface elevations have been reduced by $50 \%$ in most transects offshore the states of South Carolina, Georgia and Florida. Input wave heights are smaller in the north sections, and so is the percentage of reduction in maximum water surface elevations. Nevertheless, 


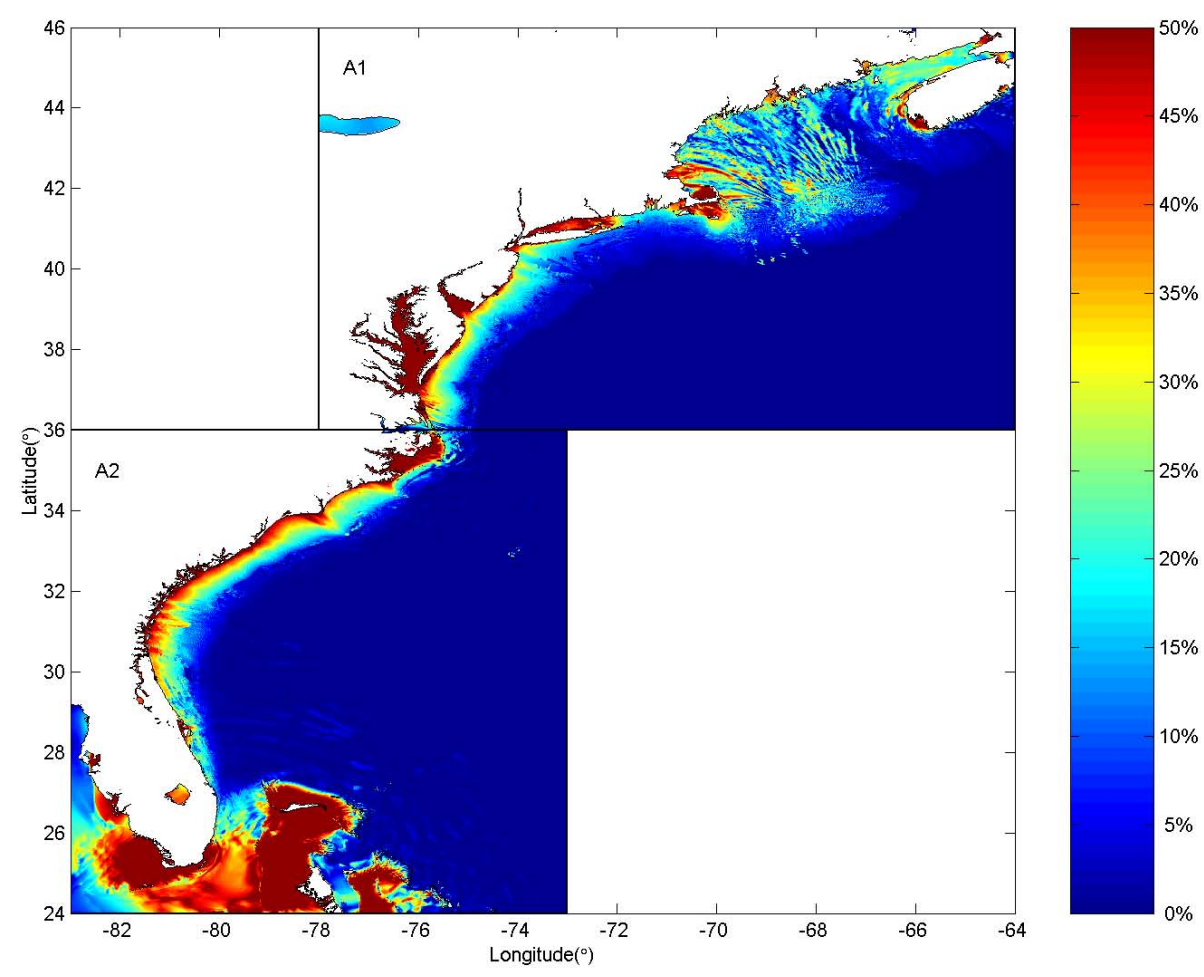

Fig. 25. Reduction in computed maximum water surface elevations due to bottom friction. The colour scale is set between 0 and $50 \%$. The values are computed as $\left|\zeta_{\max . n o n f r i c}-\zeta_{\text {max.fric }}\right| /\left|\zeta_{\text {max.nonfric }}\right| \times 100 \%$, where $\zeta_{\text {max.nonfric }}$ is the maximum water surface elevation predicted without seabed friction and $\zeta_{\max \text {.fric }}$ is that with seabed friction.

it is still over $30 \%$ in most areas. For a long wave, the total energy in an arbitrary location is proportional to the square of water surface displacement. In this event, we estimate the seabed friction dissipates more than $50 \%$ of total wave energy in most areas along the US east coast.

\subsection{Undular bores}

A dispersive wave may become disintegrated and develop into an undular bore in shallow water (e.g. Glimsdal et al., 2006; Grue et al., 2008; Løvholt et al., 2008; Madsen et al., 2008; Geist et al., 2009). The component fission waves of an undular bore have solitary wave-like shapes with very high wave heights. In the present study, wave disintegration and formation of undular bores are observed in all C-level grids. In Fig. 26, we present a series of snapshots of water surface with an undular bore originating from the second wave crest. Initially, the fission waves have a maximum wave height of nearly $10 \mathrm{~m}$ in water approximately $20 \mathrm{~m}$ deep. As these waves approach the shoreline, wave heights decay quickly as a result of seabed friction and wave breaking. The formation of undular bores may affect the runup in reverse ways. The fission waves have higher wave heights, which usually suggest higher runup. On the other hand, more wave energy may be dissipated due to seabed friction and wave breaking. This may reduce the runup. We notice that so far, the formation of undular bores and the breaking of fission waves are mostly observed in numerical studies. This process needs to be further investigated through laboratory experiments.

Observed in the present study, the lengths of fission waves fall within a range of 100-1000 m, depending on time and location. For the shorter waves, the current resolution may become insufficient. In the 1-D simulations, Geist et al. (2009) employed a resolution of $5 \mathrm{~m}$ to model the undular bores; Løvholt et al. (2008) employed variable resolutions according to local water depth, with the finest being around $4 \mathrm{~m}$. Limited by computer resources, such high resolution is not applied to the 2-D simulations in this study.

\subsection{CPU time}

All the computations are run on a computer with 8 CPUs of $2.67 \mathrm{GHz}$ speed and a memory of $24 \mathrm{~GB}$, working in the Linux 64 RH5 environment. The entire project consumes a total CPU time of $1471 \mathrm{~h}$. Parallel computing technology is not included in the current version of models. It can be an efficient way to increase the computational speed of the Boussinesq-type models (e.g. Sitanggang and Lynett, 2005; Kirby et al., 2009). 

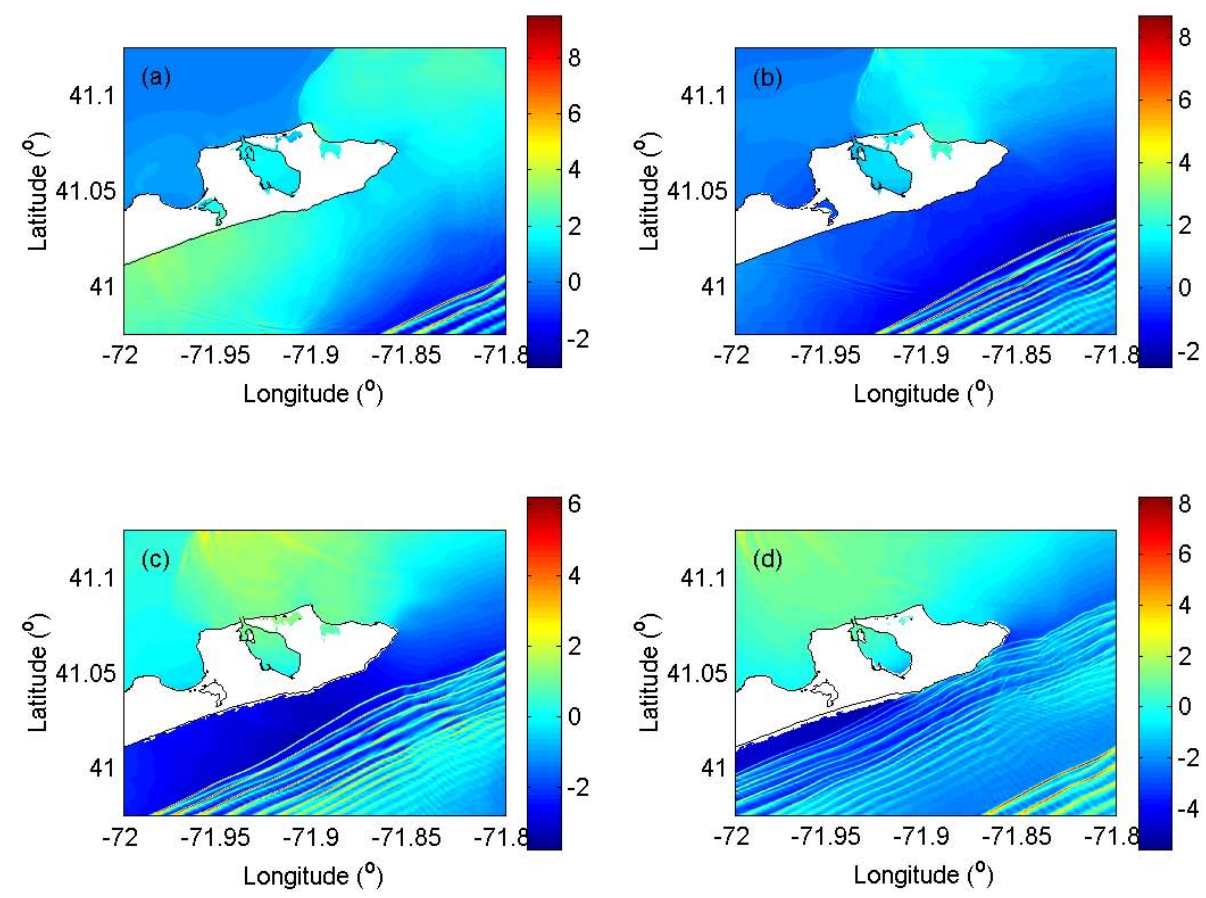

Fig. 26. Runup of an undular bore: (a)-(d) indicate the sequence in time with an interval of $200 \mathrm{~s}$.

\section{Conclusions}

In this paper, we document a numerical simulating approach employing the Boussinesq-type theories and nested computational grids. In this approach, the propagation of dispersive waves in a large domain is simulated with the weakly nonlinear model in a geographical reference frame; the nearshore propagation and coastal runup may be simulated with the fully nonlinear model in the Cartesian coordinate system. Computational results from a coarse-resolution outer grid can be transferred into a nested higher-resolution grid in forms of precomputed input boundary conditions. As a result, an entire tsunami life span can be split into several stages and respectively simulated at optimized resolutions. The numerical models and the nesting scheme are validated for analytical and experimental cases, as well as a real tsunami event.

Through this approach, we also simulate the propagation and runup of a potential tsunami which may be generated by a possible landslide on La Palma Island. We assume an initial $\mathrm{N}$-wave profile with a wave height of $700 \mathrm{~m}$, spreading west of the island around a cylindrical axis. The simulation shows the initial wave system soon develops into a leading crest and a train of oscillatory trailing waves. The trailing waves have higher wave heights, but shorter wavelengths. Before reaching the west brim of deep ocean, the leading peak has a height of $2.2 \mathrm{~m}$ above still water level, and a wavelength of $220 \mathrm{~km}$, both measured along the longitude going through the cylindrical axis. The present study indicates the seabed friction over the continental shelf dissipates over $50 \%$ of the total wave energy and, thus, greatly reduces tsunami impact on the US east coast. Considering that most coastal communities along the US east coast are situated on low elevations, this tsunami may cause severe flooding. Wave disintegration and formation of undular bores are observed in the highresolution simulations. The lengths of component waves in the undular bores fall within a range of 100-1000 m.

In this study, the initial wave field near La Palma Island is estimated based on a numerical simulation by Gisler et al. (2006). The volume of landslide is estimated to be $365 \mathrm{~km}^{3}$. This scenario may represent a potential hazard of very low probability.

\section{Appendix A}

\section{The Boussinesq equations in geographical coordinates}

Nwogu's (1993) Boussinesq equations retain the lowest order of nonlinear and dispersive terms, and assume $O(\epsilon)=O\left(\mu^{2}\right)$. The water velocities $\boldsymbol{u}_{\alpha}=\left(u_{\alpha}, v_{\alpha}\right)$ are described at the reference water level $z_{\alpha} \cong-0.531 h$, where $h$ is the still water depth. In this study, we redefine this parameter in a slightly different manner, i.e., $z_{\alpha} \cong-0.531 h+0.469 \zeta$, where $\zeta$ is the water surface elevation. This guarantees that the reference water level is always within the water column during the wave runup and drawdown. In basin scale, the curvature of the Earth surface and the Coriolis effect may become important. In this situation, we convert the original 
equations into geographical coordinates $(\phi, \theta)$. The conversion process is straightforward by employing the operators

$\nabla()=\frac{i}{R \cos \theta} \frac{\partial}{\partial \phi}()+\frac{j}{R} \frac{\partial}{\partial \theta}()$,

$\nabla \cdot \boldsymbol{u}_{\alpha}=\frac{1}{R \cos \theta}\left[\frac{\partial u_{\alpha}}{\partial \phi}+\frac{\partial}{\partial \theta}\left(v_{\alpha} \cos \theta\right)\right]$,

$\boldsymbol{k} \cdot\left(\nabla \times \boldsymbol{u}_{\alpha}\right)=\frac{1}{R \cos \theta}\left[\frac{\partial v_{\alpha}}{\partial \phi}-\frac{\partial}{\partial \theta}\left(u_{\alpha} \cos \theta\right)\right]$,

where $\boldsymbol{i}$ and $\boldsymbol{j}$ are the unit vectors in $\phi$ and $\theta$ directions, respectively, and $\boldsymbol{k}$ is that normal to the Earth surface. Also note that the tensor $\left(\boldsymbol{u}_{\alpha} \cdot \nabla\right) \boldsymbol{u}_{\alpha}$ shall be rewritten as

$\left(\boldsymbol{u}_{\alpha} \cdot \nabla\right) \boldsymbol{u}_{\alpha}=\frac{1}{2} \nabla\left(\boldsymbol{u}_{\alpha} \cdot \boldsymbol{u}_{\alpha}\right)+\left[\boldsymbol{k} \cdot\left(\nabla \times \boldsymbol{u}_{\alpha}\right)\right]\left(\boldsymbol{k} \times \boldsymbol{u}_{\alpha}\right),(\mathrm{A}$

before the operators are applied. The Boussinesq equations read as follows in the new form,

$$
\begin{aligned}
& \frac{\partial H}{\partial t}+\frac{1}{R \cos \theta}\left[\frac{\partial}{\partial \phi}\left(H u_{\alpha}\right)+\frac{\partial}{\partial \theta}\left(H v_{\alpha} \cos \theta\right)\right] \\
& +\frac{1}{R^{3} \cos ^{3} \theta} \frac{\partial}{\partial \phi}\left\{H\left(\frac{z_{\alpha}^{2}}{2}-\frac{h^{2}}{6}\right)\left[\frac{\partial^{2} u_{\alpha}}{\partial \phi^{2}}+\frac{\partial^{2}}{\partial \phi \partial \theta}\left(v_{\alpha} \cos \theta\right)\right]\right. \\
& \left.+H\left(z_{\alpha}+\frac{h}{2}\right)\left[\frac{\partial^{2}}{\partial \phi^{2}}\left(h u_{\alpha}\right)+\frac{\partial^{2}}{\partial \phi \partial \theta}\left(h v_{\alpha} \cos \theta\right)\right]\right\} \\
& +\frac{1}{R^{3} \cos \theta} \frac{\partial}{\partial \theta}\left\{H\left(\frac{z_{\alpha}^{2}}{2}-\frac{h^{2}}{6}\right)\left[\frac{\partial u_{\alpha}}{\partial \phi}+\frac{\partial}{\partial \theta}\left(v_{\alpha} \cos \theta\right)\right] \tan \theta\right. \\
& +H\left(\frac{z_{\alpha}^{2}}{2}-\frac{h^{2}}{6}\right)\left[\frac{\partial^{2} u_{\alpha}}{\partial \phi \partial \theta}+\frac{\partial^{2}}{\partial \theta^{2}}\left(v_{\alpha} \cos \theta\right)\right] \\
& +H\left(z_{\alpha}+\frac{h}{2}\right)\left[\frac{\partial}{\partial \phi}\left(h u_{\alpha}\right)+\frac{\partial}{\partial \theta}\left(h v_{\alpha} \cos \theta\right)\right] \tan \theta \\
& \left.+H\left(z_{\alpha}+\frac{h}{2}\right)\left[\frac{\partial^{2}}{\partial \phi \partial \theta}\left(h u_{\alpha}\right)+\frac{\partial^{2}}{\partial \theta^{2}}\left(h v_{\alpha} \cos \theta\right)\right]\right\}=0, \\
& \frac{\partial u_{\alpha}}{\partial t}+\frac{1}{R \cos \theta}\left[u_{\alpha} \frac{\partial u_{\alpha}}{\partial \phi}+v_{\alpha} \frac{\partial u_{\alpha}}{\partial \theta} \cos \theta\right]-\frac{u_{\alpha} v_{\alpha}}{R} \tan \theta \\
& +\frac{g}{R \cos \theta} \frac{\partial \zeta}{\partial \phi}+\frac{1}{R^{2} \cos ^{2} \theta} \frac{\partial}{\partial t}\left\{\frac{z_{\alpha}^{2}}{2}\left[\frac{\partial^{2} u_{\alpha}}{\partial \phi^{2}}+\frac{\partial^{2}}{\partial \phi \partial \theta}\left(v_{\alpha} \cos \theta\right)\right]\right. \\
& \left.+z_{\alpha}\left[\frac{\partial^{2}}{\partial \phi^{2}}\left(h u_{\alpha}\right)+\frac{\partial^{2}}{\partial \phi \partial \theta}\left(h v_{\alpha} \cos \theta\right)\right]\right\} \\
& +R_{\mathrm{f} x}-f v_{\alpha}=0 \\
& \frac{\partial v_{\alpha}}{\partial t}+\frac{1}{R \cos \theta}\left[u_{\alpha} \frac{\partial v_{\alpha}}{\partial \phi}+v_{\alpha} \frac{\partial v_{\alpha}}{\partial \theta} \cos \theta\right]+\frac{u_{\alpha}^{2}}{R} \tan \theta \\
& +\frac{g}{R} \frac{\partial \zeta}{\partial \theta}+\frac{1}{R^{2} \cos ^{2} \theta} \frac{\partial}{\partial t}\left\{\frac{z_{\alpha}^{2}}{2}\left[\frac{\partial u_{\alpha}}{\partial \phi}+\frac{\partial}{\partial \theta}\left(v_{\alpha} \cos \theta\right)\right] \sin \theta\right. \\
& +\frac{z_{\alpha}^{2}}{2}\left[\frac{\partial^{2} u_{\alpha}}{\partial \phi \partial \theta}+\frac{\partial^{2}}{\partial \theta^{2}}\left(v_{\alpha} \cos \theta\right)\right] \cos \theta \\
& +z_{\alpha}\left[\frac{\partial}{\partial \phi}\left(h u_{\alpha}\right)+\frac{\partial}{\partial \theta}\left(h v_{\alpha} \cos \theta\right)\right] \sin \theta \\
& \left.+z_{\alpha}\left[\frac{\partial^{2}}{\partial \phi \partial \theta}\left(h u_{\alpha}\right)+\frac{\partial^{2}}{\partial \theta^{2}}\left(h v_{\alpha} \cos \theta\right)\right] \cos \theta\right\} \\
& +R_{\mathrm{f} y}+f u_{\alpha}=0 \text {, }
\end{aligned}
$$

where $H=h+\zeta$ is the total water depth, $g$ is the gravitational acceleration, $R$ is the radius of the Earth, $f=2 \omega \sin \theta$ is the Coriolis coefficient and $\omega$ is the angular speed of Earth rotation. The lose due to bottom friction, $\mathbf{R}_{\mathrm{f}}$, can be computed as

$\mathbf{R}_{\mathrm{f}}=C_{\mathrm{f}} \frac{\boldsymbol{u}_{b}\left|\boldsymbol{u}_{b}\right|}{H}$,

in which the horizontal water velocity along seabed $\boldsymbol{u}_{b}$ can be determined as

$$
\begin{aligned}
& u_{b}=u_{\alpha} \\
& +\frac{z_{\alpha}^{2}-h^{2}}{2 R^{2} \cos ^{2} \theta}\left[\frac{\partial^{2} u_{\alpha}}{\partial \phi^{2}}+\frac{\partial^{2}}{\partial \phi \partial \theta}\left(v_{\alpha} \cos \theta\right)\right] \\
& +\frac{h+z_{\alpha}}{R^{2} \cos ^{2} \theta}\left[\frac{\partial^{2}}{\partial \phi^{2}}\left(h u_{\alpha}\right)+\frac{\partial^{2}}{\partial \phi \partial \theta}\left(h v_{\alpha} \cos \theta\right)\right] \\
& v_{b}=v_{\alpha} \\
& +\frac{z_{\alpha}^{2}-h^{2}}{2 R^{2} \cos ^{2} \theta}\left\{\left[\frac{\partial^{2} u_{\alpha}}{\partial \phi \partial \theta}+\frac{\partial^{2}}{\partial \theta^{2}}\left(v_{\alpha} \cos \theta\right)\right] \cos \theta\right. \\
& \left.+\left[\frac{\partial u_{\alpha}}{\partial \phi}+\frac{\partial}{\partial \theta}\left(v_{\alpha} \cos \theta\right)\right] \sin \theta\right\} \\
& +\frac{h+z_{\alpha}}{R^{2} \cos ^{2} \theta}\left\{\left[\frac{\partial^{2}}{\partial \phi \partial \theta}\left(h u_{\alpha}\right)+\frac{\partial^{2}}{\partial \theta^{2}}\left(h v_{\alpha} \cos \theta\right)\right] \cos \theta\right. \\
& \left.+\left[\frac{\partial}{\partial \phi}\left(h u_{\alpha}\right)+\frac{\partial}{\partial \theta}\left(h v_{\alpha} \cos \theta\right)\right] \sin \theta\right\} .
\end{aligned}
$$

Acknowledgements. We are grateful to S. N. Ward, F. Løvholt and U. Kânoğlu for their invaluable comments and revision suggestions on this paper. The first author thanks the National Research Council for its support through the Research Associateship Program. This study is partially funded by the Pacific Marine Environmental Laboratory (PMEL) and the Joint Institute for the Study of the Atmosphere and Ocean (JISAO) under NOAA Cooperative Agreement No. NA10OAR4320148, Contribution \#3569 (PMEL), \#1870 (JISAO) and the US Nuclear Regulatory Commission, Office of Nuclear Regulatory Research under Interagency Agreement RES-07-004 Project N6401.

Edited by: S. Tinti

Reviewed by: F. Løvholt and S. Ward

\section{References}

Abadie, S., Gandon, C., Grilli, S. T., Fabre, R., Riss, J., Tric, E., Morichon, D., and Glockner, S.: 3D simulations of waves generated by subaerial mass failures. Application to La Palma case, Proc. 31st Intl. Conf. on Coastal Eng., 31 August-5 September 2008, Hamburg, Germany, 2008.

Abadie, S., Morichon, D., Grilli, S., and Glockner, S.: Numerical simulation of waves generated by landslides using a multiplefluid Navier-Stokes model, Coastal Eng., 57, 779-794, 2010.

Beji, S. and Battjes, J. A.: Experimental investigatin of wave propagation over a bar, Coastal Eng., 19, 151-162, 1993.

Beji, S. and Battjes, J. A.: Numerical simulation of nonlinear wave propagation over a bar, Coastal Eng., 23, 1-16, 1994. 
Briggs, M. J., Synolakis, C. E., and Harkins, G. S.: Tsunami runup on a conical island, Proc. Waves - Physical and Numerical Modelling, International Association for Hydraulic Research, Delft, The Netherlands, 446-455, 1994.

Bryant, E.: Tsunami: The Underrated Hazard, Cambridge University Press, 320 pp., 2001.

Burwell, D., Tolkova, E., and Chawla, A.: Diffusion and dispersion characterization of a numerical tsunami model, Ocean Modell., 19, 10-30, 2007.

Carrier, G. F., Wu, T. T., and Yeh, H.: Tsunami runup-up and drawdown on a plane beach, J. Fluid Mech., 475, 79-99, 2003.

Chen, Q., Kirby, J. T., Dalrymple, R. A., Kennedy, A. B., and Chawla, A.: Boussinesq modelling of wave transformation, breaking, and runup, II: 2D, J. Waterwy. Port Coastal Ocean Eng., 126(1), 48-56, 2000.

Dalrymple, R. A., Grilli, S. T., and Kirby, J. T.: Tsunamis and challenges for accurate modelling, Oceanography, 19(1), 142-151, 2006.

Fritz, H. M., Hager, W. H., and Minor, H.-E.: Near field characteristics of landslide generated impulse waves, J. Waterwy. Port Coastal Ocean Eng., 130, 287-302, 2004.

Fuhrman, D. R. and Madsen, P. A.: Tsunami generation, propagation, and run-up with a high-order Boussinesq model, Coastal Eng., 56, 747-758, 2009.

Gayer, G., Leschka, S., Nöhren, I., Larsen, O., and Günther, H.: Tsunami inundation modelling based on detailed roughness maps of densely populated areas, Nat. Hazards Earth Syst. Sci., 10, 1679-1687, doi:10.5194/nhess-10-1679-2010, 2010.

Geist, E. L., Lynett, P. J., and Chaytor, J. D.: Hydrodynamic modelling of tsunamis from the Currituck Landslide, Mar. Geol., 264, 41-52, 2009.

Gica, E., Spillane, M. C., Titov, V. V., Chamberlin, C. D., and Newman, J. C.: Development of the forecast propagation database for NOAA's short-term inundation forecast for tsunamis (SIFT), Tech. Memo. OAR PMEL-139, Gov. Print. Off., Seattle, WA, 89 pp., 2008.

Gisler, G., Weaver, R., and Gittings, M.: SAGE calculations of the tsunami threat from La Palma, Sci. Tsunami Hazards, 24, 288301, 2006.

Glimsdal, S., Pedersen, G. K., Atakan, K., Harbitz, C. B., Langtangen, H. P., and Løvholt, F.: Propagation of the Dec. 26, 2004, Indian Ocean Tsunami: Effects of dispersion and source characteristics, Int. J. Fluid Mech. Res., 33, 15-43, 2006.

Gobbi, M. F. and Kirby, J. T.: Wave evolution over submerged sills: Tests of a high-order Boussinesq model, Coastal Eng., 37, 57-96, 1999.

Grilli, S. T. and Watts, P.: Tsunami generation by submarine mass failure. I: Modeling experimental validation, and sensitivity analyses, J. Waterwy. Port Coastal Ocean Eng., 131(6), 283-297, 2005.

Grilli, S. T., Vogelmann, S., and Watts, P.: Development of a 3D numerical wave tank for modelling tsunami generation by underwater landslides, Eng. Anal. Bound. Elemt., 26, 301-313, 2002.

Grilli, S. T., Ioualalen, M., Asavanant, J., Shi, F.-Y., Kirby, J. T., and Watts, P.: Source constraints and model simulation of the December 26, 2004, Indian Ocean Tsunami, J. Waterwy. Port Coastal Ocean Eng., 133(6), 414-428, 2007.
Grilli, S. T., Dubosq, S., Pophet, N., Pérignon, Y., Kirby, J. T., and Shi, F.: Numerical simulation and first-order hazard analysis of large co-seismic tsunamis generated in the Puerto Rico trench: near-field impact on the North shore of Puerto Rico and far-field impact on the US East Coast, Nat. Hazards Earth Syst. Sci., 10, 2109-2125, doi:10.5194/nhess-10-2109-2010, 2010.

Grue, J., Peliovsky, E. N., Fructus, D., Talipova, T., and Kharif, C.: Formulation of undular bores and solitary waves in the Strait of Malacca caused by the 26 December 2004 Indian Ocean tsunami, J. Geophys. Res., 113, C05008, doi:10.1029/2007JC004343, 2008.

Imamura, F.: Simulation of wave-packet propagation along sloping beach by TUNAMI-code, in: Long-Wave Runup Models, edited by: Yeh, H., Liu, P. L. F., and Synolakis, C., World Scientific, 231-241, 1996.

Imran, J., Harff, P., and Parker, G.: A numerical model of submarine debris flow with graphical user interface, Comput. Geosci., 27, 717-729, 2001.

Ioualalen, M., Asavanant, J., Kaewbanjak, N., Grilli, S. T., Kirby, J. T., and Watts, P.: Modeling the 26 December 2004 Indian Ocean tsunami: Case study of impact in Thailand, J. Geophys. Res., 112, C07024, doi:10.1029/2006JC003850, 2007.

Jiang, L. and LeBlond, P. H.: The coupling of a submarine slide and the surface water waves which it generates, J. Geophys. Res., 97, 12731-12744, 1992.

Jiang, L. and LeBlond, P. H.: Numerical modelling of an underwater Bingham plastic mudslide and the waves which it generates, J. Geophys. Res., 98, 10303-10317, 1993.

Kânoğlu, U. and Synolakis, C. E.: Long wave runup on piecewise linear topographies, J. Fluid Mech., 374, 1-28, 1998.

Kennedy, A. B., Chen, Q., Kirby, J. T., and Dalrymple, R. A.: Boussinesq modelling of wave transformation, breaking, and runup, I: 1D, J. Waterwy. Port Coastal Ocean Eng., 126, 39-47, 2000.

Kirby, J. T., Pophet, N., Shi, F., and Grilli, S. T.: Basin scale tsunami propagation modelling using Boussinesq models: Parallel implementation in spherical coordinates, Proc. WCCE-ECCE-TCCE Joint Conf. on Earthquake and Tsunami, 22-24 June 2008, Istanbul, Turkey, 2009.

Lin, P.-Z. and Man, C.-J.: A staggered-grid numerical algorithm for the extended Boussinesq equations, Appl. Math. Modell., 31, 349-369, 2007.

Liu, P. L.-F., Cho, Y.-S., Briggs, M. J., Kanoglu, U., and Synolakis, C. E.: Runup of solitary waves on a circular island, J. Fluid Mech., 302, 259-285, 1995.

Liu, P. L.-F., Woo, S.-B., and Cho, Y.-S.: Computer programs for tsunami propagation and inundatin, Tech. Memo, Cornell University, 104 pp., 1998.

Liu, P. L.-F., Wu, T.-R., Raichlen, F., Synolakis, C. E., and Borrero, J. C.: Runup and rundown generated by three-dimensional sliding masses, J. Fluid Mech., 536, 107-144, 2005.

Liu, P. L.-F., Yeh, H., and Synolakis, C. E.: Benchmark problems, Advanced Numerical Models for Simulating Tsunami Waves and Runup, in: Advances in Coastal and Ocean Engineering, edited by: Liu, P. L. F., Yeh, H., and Synolakis, C., World Scientific, 223-236, 2008.

Løvholt, F., Pedersen, G., and Gisler, G.: Oceanic propagation of a potential tsunami from the La Palma Island, J. Geophys. Res., 113, C09026, doi:10.1029/2007JC004603, 2008. 
Løvholt, F., Pedersen, G., and Glimsdal, S.: Coupling of dispersive tsunami propagation and shallow water coastal response, Proceedings of the "Caribbean Waves 2008" Workshop in Guadeloupe, December 2008, edited by: Zahibo, N., Pelinovsky, E., Yalciner, A., and Titov, V., Open Oceanogr. J., 4, 71-82, 2010.

Lynett, P. J.: A multi-layer approach to modelling generation, propagation, and interaction of water waves, Ph.D. dissertation, Cornell University, 2002.

Lynett, P. J. and Liu, P. L.-F.: A numerical study of submarinelandslide-generated waves and run-up, P. Roy. Soc. Lond. A, 458, 2885-2910, 2002.

Lynett, P. J., Wu, T.-R., and Liu, P. L.-F.: Modeling wave runup with depth-integrated equations, Coastal Eng., 46, 89-107, 2002.

Mader, C. L.: A landslide model for the 1975 Hawaii tsunami, Sci. Tsunami Hazards, 2, 71-77, 1984.

Mader, C. L.: Modeling the La Palma landslide tsunami, Sci. Tsunami Hazards, 19, 150-170, 2001.

Madsen, P. A., Fuhrman, D. R., and Schäffer, H. A.: On the solitary wave paradigm for tsunamis, J. Geophys. Res., 113, C12012, doi:10.1029/2008JC004932, 2008.

Miles, J. W.: Solitary waves, Ann. Rev. Fluid Mech., 12, 11-43, 1980.

Nwogu, O.: Alternative form of Boussinesq equations for nearshore wave propagation, J. Waterwy. Port Coastal Ocean Eng., 119, 618-638, 1993.

Pedersen, G. and Løvholt, F.: Documentation of a global Boussinesq solver. Preprint Series in of Applied Mathematics, No. 1, Dept. of Math., U. of Oslo, Norway, 69 pp., 2008.

Rabinovich, A. B., Thomson, R. E., Kulikov, E. A., Bornhold, B. D., and Fine, I. V.: The landslide-generated tsunami of November 3, 1994 in Skagway Harbor, Alaska: A case study, Geophys. Res. Lett., 26, 3009-3012, 1999.

Roeber, V., Cheung, K. F., and Kobayashi, M. H.: Shock-capturing Boussinesq-type model for nearshore wave processes, Coastal Eng., 57, 407-423, 2010.

Savage, S. B. and Hutter, K.: The motion of a finite mass of granular material down a rough incline, J. Fluid Mech., 199, 177-215, 1989.

Shapiro, R.: Smoothing, filtering, and boundary effects, Rev. Geophys. Space Phys., 8, 359-87, 1970.

Shi, F., Dalrymple, R. A., Kirby, J. T., Chen, Q., and Kennedy, A.: A fully nonlinear Boussinesq model in generalized curvilinear coordinates, Coastal Eng., 42, 337-358, 2002.

Sitanggang, K. I. and Lynett, P.: Parallel computation of a highly nonlinear Boussinesq equation model through domain decomposition, Int. J. Numer. Meth. Fluids, 49, 57-74, 2005.

Skvortsov, A. and Bornhold, B.: Numerical simulation of the landslide-generated tsunami in Kitimat Arm, British Columbia, Canada, 27 April 1975, J. Geophys. Res., 112, F02028, doi:10.1029/2006JF000499, 2007.

Synolakis C. E. and Bernard, E. N.: Tsunami science before and beyond Boxing Day 2004, Philos. T. Roy. Soc. A, 364, 22312265, 2006.

Synolakis, C. E., Bardet, J. P., Borrero, J. C., Davies, H., Okal, E. A., Silver, E. A., Sweet, S., and Tappin, D. R.: Slump origin of the 1998 Papua New Guinea tsunami, P. Roy. Soc. A., 458, 763-789, 2002.
Tang, L., Titov, V. V., and Chamberlin, C. D.: Development, testing, and application of site-specific tsunami inundation models for real-time forecasting, J. Geophys. Res., 114, C12025, doi:10.1029/2009JC005476, 2009.

Teng, M. H.: Solitary wave solution to Boussinesq equations, J. Waterway, Port Coastal Ocean Eng., 123, 138-141, 1997.

Thacker, W. C.: Some exact solutions to the nonlinear shallowwater wave equations, J. Fluid Mech., 107, 499-508, 1981.

Titov, V. V. and González, F. I.: Implementation and testing of the Method of Splitting Tsunami (MOST) model, Tech. Memo. ERL PMEL-112, Gov. Print. Off., Seattle, WA, 11 pp., 1997.

Titov, V. V. and Synolakis, C. E.: Numerical modelling of tidal wave runup, J. Waterway Port Coastal Ocean Eng., 124, 157$171,1998$.

Titov, V. V., Rabinovich, A. B., Mofjeld, H. O., Thomson, R. E., and González, F. I.: The global reach of the 26 December 2004 Sumatra tsunami, Science, 309, 2045-2048, 2005.

Titov, V. V., Moore, C. W., Greenslade, D. J. M., Pattiaratchi, C., Badal, R., Synolakis, C. E., and Kânoğlu, U.: A new tool for inundation modelling: Community Modeling Interface for Tsunamis (ComMIT), Pure Appl. Geophys., doi:10.1007/s00024-011-0292-4, in press, 2011.

Urgeles, R., Masson, D. G., Canals, M., Watts, A. B., and Le Bas, T.: Recurrent large-scale landslideing on the west flank of La Palma, Canary Island, J. Geophy. Res., 104, 25331-25348, 1999.

Ward, S. N.: Landslide tsunami, J. Geophys. Res., 106, 1120111215, 2001.

Ward, S. N. and Day, S.: Cumbre Vieja Volcano - Potential collapse and tsunami at La Palma, Canary Islands, Geophys. Res. Lett., 28, 3397-3400, 2001.

Ward, S. N. and Day, S.: Particulate kinematic simulations of debris avalanches: interpretation of deposits and landslide seismic signals of Mount Saint Helens, 1980 May 18, Geophys. J. Int., 167, 991-1004, 2006.

Watts, P., Grilli, S. T., Kirby, J. T., Fryer, G. J., and Tappin, D. R.: Landslide tsunami case studies using a Boussinesq model and a fully nonlinear tsunami generation model, Nat. Hazards Earth Syst. Sci., 3, 391-402, doi:10.5194/nhess-3-391-2003, 2003.

Watts, P., Grilli, S. T., Tappin, D. R., and Fryer, G. J.: Tsunami generation by submarine mass failure, Part II: Predictive equations and case studies, J. Waterwy Port Coastal Ocean Eng., 131, 298-310, 2005.

Wei, G. and Kirby, J. T.: A time-dependent numerical code for extended Boussinesq equations, J. Waterway Port Coastal Ocean Eng., 120, 251-261, 1995.

Wei, G., Kirby, J. T., Grilli, S. T., and Subramanya, R.: A fully nonlinear Boussinesq model for surface waves, Part 1. Highly nonlinear unsteady waves, J. Fluid Mech., 294, 71-92, 1995.

Wei, G., Kirby, J. T., and Sinha, A.: Generation of waves in Boussinesq models using a source function method, Coastal Eng., 36, 271-299, 1999.

Wünnemann, K., Collins, G. S., and Helosh, H. J.: A strain-based porosity model for use in hydrocode simulations of impacts and implications for transient crater growth in porous targets, Icarus, 180, 514-527, 2006.

Yamazaki, Y., Kowalik, Z., and Cheung, K. F.: Depth-integrated, non-hydrostatic model for wave breaking and run-up, Int. J. Numer. Meth. Fluids, 61, 473-497, 2009. 
Yuk, D., Yim, S. C., and Liu, P. L.-F.: Numerical modelling of submarine mass-movement generated waves using RANS model, Comput. Geosci., 32, 927-935, 2006.

Zelt, J. A.: The runup of breaking and nonbreaking solitary waves, Coastal Eng., 125, 205-246, 1991.
Zhou, H. and Teng, M. H.: Extended fourth-order depth-integrated model for water waves and currents generated by submarine landsldies, J. Eng. Mech., 136, 506-516, 2010. 